\title{
The Emergence of Shallow Easterly Jets within QBO Westerlies
}

\author{
Peter HitchCOCK ${ }^{\mathrm{a}}$ \\ National Center for Atmospheric Research, Boulder, Colorado \\ PETER H. HAYNES \\ Department of Applied Mathematics and Theoretical Physics, University of Cambridge, Cambridge, United Kingdom \\ WILLIAM J. RANDEL \\ National Center for Atmospheric Research, Boulder, Colorado \\ THOMAS BIRNER \\ Department of Atmospheric Science, Colorado State University, Fort Collins, Colorado
}

(Manuscript received 5 April 2017, in final form 29 September 2017)

\begin{abstract}
A configuration of an idealized general circulation model has been obtained in which a deep, stratospheric, equatorial, westerly jet is established that is spontaneously and quasi-periodically disrupted by shallow easterly jets. Similar to the disruption of the quasi-biennial oscillation (QBO) observed in early 2016, meridional fluxes of wave activity are found to play a central role. The possible relevance of two feedback mechanisms to these disruptions is considered. The first involves the secondary circulation produced in the shear zones on the upper and lower flanks of the easterly jet. This is found to play a role in maintaining the aspect ratio of the emerging easterly jet. The second involves the organization of the eddy fluxes by the mean flow: the presence of a weak easterly anomaly within a tall, tropical, westerly jet is demonstrated to produce enhanced and highly focused wave activity fluxes that reinforce and strengthen the easterly anomalies. The eddies appear to be organized by the formation of strong potential vorticity gradients on the subtropical flanks of the easterly anomaly. Similar wave activity and potential vorticity structures are found in the ERA-Interim for the observed QBO disruption, indicating this second feedback was active then.
\end{abstract}

\section{Introduction}

The quasi-biennial oscillation $(\mathrm{QBO})$ is the dominant pattern of variability in the tropical lower stratosphere, characterized by alternating descent of easterly and westerly zonal jets with a period of roughly 28 months. In early 2016, a shallow broad easterly jet emerged in the tropical lower stratosphere, disrupting the QBO by splitting a descending westerly jet roughly in half. This occurrence was unprecedented in more

\footnotetext{
${ }^{a}$ Current affiliation: Laboratoire de Météorologie Dynamique, Ecole Polytechnique, Paris, France.
}

Corresponding author: Peter Hitchcock, peter.hitchcock@ lmd.polytechnique.fr than 50 years of observations (Newman et al. 2016; Osprey et al. 2016).

We report here on a series of integrations with an idealized general circulation model (a dry dynamical core) that produce events that share dynamical features with the observed disruption. These integrations were originally performed to study extratropical processes, not the tropical circulations that resulted. They, along with the further dynamical analysis they prompted, nonetheless suggest some valuable insights into the observed disruption.

In these integrations, the model forms a deep narrow westerly jet, confined to within $15^{\circ}$ of the equator, which is quasi-periodically disrupted by shallow, broad easterly jets (Fig. 1a). These form spontaneously just above the base of the westerly jet then migrate upward. Figure 1a also shows the meridional component 


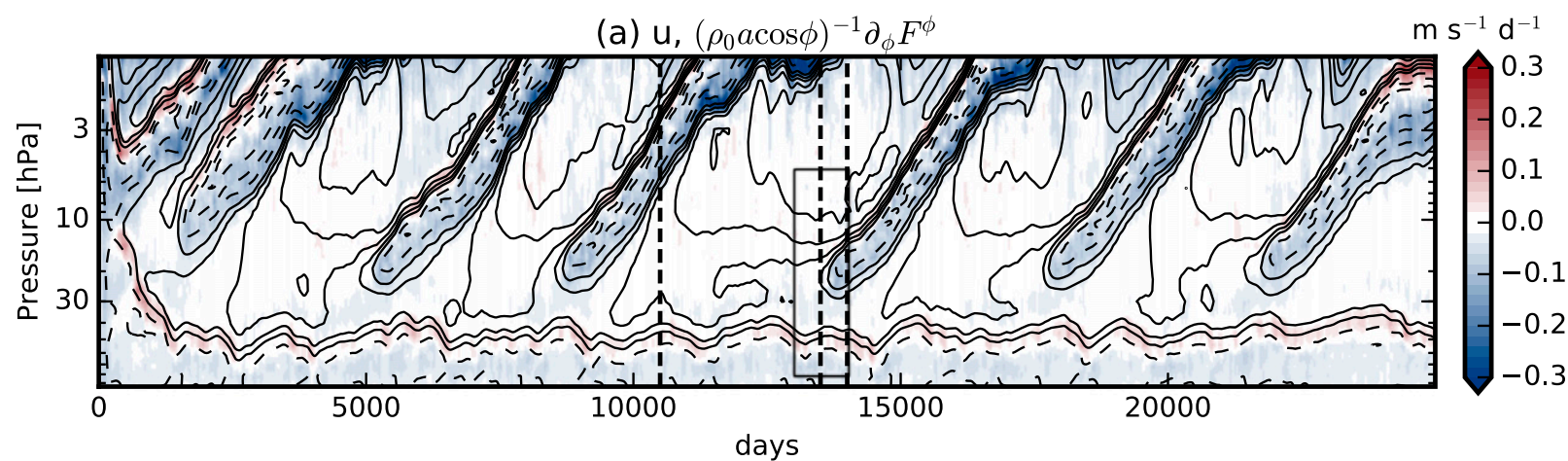

(b) $\mathrm{u},\left(\rho_{0} a \cos \phi\right)^{-1} \partial_{\phi} F^{\phi}$

$\mathrm{m} \mathrm{s}^{-1} \mathrm{~d}^{-1}$

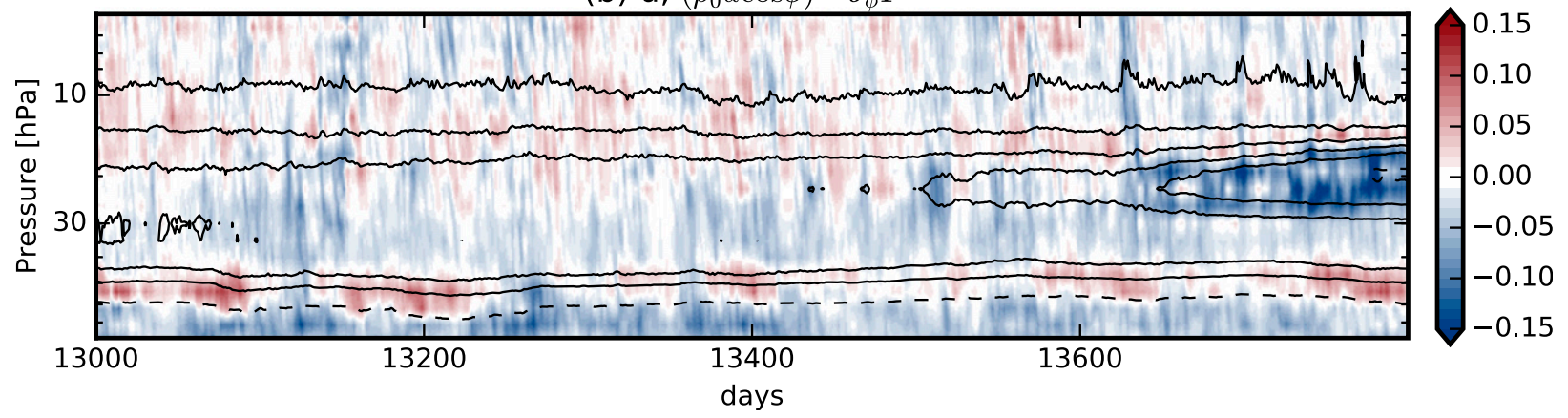

FIG. 1. (a) Zonal-mean zonal wind (contours; interval is $5 \mathrm{~m} \mathrm{~s}^{-1}$ for positive values and $10 \mathrm{~m} \mathrm{~s}^{-1}$ for negative values) and zonal wind tendency due to the meridional divergence of the meridional component of the E-P flux (shading), averaged over $5^{\circ} \mathrm{S}-5^{\circ} \mathrm{N}$, from a dry dynamical core integration (see text for details). The winds are smoothed by a 50-day low-pass exponential filter, while the flux divergence is smoothed with a causal 50-day low-pass exponential filter (see section 2d). The times indicated by the vertical dashed lines are highlighted in Fig. 2. (b) As in (a), but focusing on an 800-day period prior to a disruption, outlined by the gray box in (a). In (b), the winds are not smoothed, and the causal exponential filter used for the flux divergences has a 10-day time scale.

of the wave-induced forcing in the model simulation. In contrast to the standard picture of QBO dynamics, and as is thought to be the case in the observed disruption (Osprey et al. 2016), these meridional fluxes play a central role in the emergence of the easterly jets.

One feature common to the observed event and the disruptions in the idealized model is the shallow vertical length scale of the easterly jets. In the idealized model, the tropical upwelling is substantially modified within the easterly jets-enough so that there is net downwelling in the westerly shear zone on their upper flanks. This "secondary circulation" is well known to produce asymmetries between the descent of easterly and westerly phases of the QBO (Reed 1964; Plumb and Bell 1982; Dunkerton 1991). Indeed, Wallace (1967, p. 178) concluded that this causes westerly shear to propagate downward more rapidly than easterly shear and that this "causes easterly regimes to decrease in vertical extent as they move downwards." We consider here, through explicit calculations with a one-dimensional advective model, whether this secondary circulation could be determining the vertical scale of the easterly jets. This leads to the identification of a threshold forcing strength, above which the advective effects of secondary circulation play an important role in determining the aspect ratio of the jet.

Further consideration of Fig. 1 supports the idea of a threshold, which, once passed, triggers a feedback process that then leads to the full development of the easterly jet. The time interval between successive disruptions seen in Fig. 1a is variable, ranging from 3500 to nearly 5000 days. However, the evolution of the easterly jet over the period of a few hundred days around the time of the reversal of the winds is quite similar from event to event. This time scale is still long compared to typical time scales of fluctuations in the equatorial wave driving (Fig. 1b), suggesting that the evolution of the jet during this period is not determined by a single extreme wave-driving event. Moreover, once the jet is established, there is consistently enhanced wave driving focused on the easterly jet, suggesting the waves are being systematically organized by the mean flow. We demonstrate explicitly that this is indeed the case in the idealized model and present evidence that a similar feedback was active during the observed event. This process is distinct from the threshold described in the previous paragraph. 
The leading-order influence of extratropical wave fluxes on QBO winds during both the disruption in early 2016 and disruptions in the dry dynamical core is interesting in light of early research on the mechanisms behind the QBO. Many researchers (e.g., Wallace 1967) sought to explain the QBO by assuming that the dominant wave driving is due to horizontal eddy momentum fluxes (of extratropical origin). But convincing model experiments by Wallace and Holton (1968) showed that this mechanism was simply not viable without also assuming this wave driving also moves downward. This led the way to the Lindzen and Holton (1968) formulation of a model in which the dominant wave forcing came from within the tropics and naturally moved downward with the QBO winds, thereby producing a realistic QBO.

The outline of this paper is as follows. Section 2 describes in detail the base configuration of the dry dynamical core. Section 3 discusses the phenomenology of the disruptions in this configuration, focusing on the structure of the wave driving and of the secondary circulation during the disruptions. Section 4 considers the role of the secondary circulation in setting the structure and evolution of the easterly jet by considering the response of a one-dimensional advective model to an imposed force. Section 5 demonstrates the feedback between the waves and the mean flow in the dry dynamical core through two additional sets of integrations. The first set considers the response of the tall westerly equatorial jet to a fixed imposed forcing of various strengths. For sufficiently strong forcing, the wave forcing becomes highly organized by the mean flow, amplifying the imposed force. The second set considers the response of the waves to a fixed equatorial zonal wind structure, clarifying the structure of the feedback. Section 6 then discusses the observed event as captured by the ERAInterim (Dee et al. 2011) in light of these results. The structure of anomalous Eliassen-Palm (E-P) fluxes are found to closely resemble those associated with the wave-mean flow feedback identified in the idealized model, suggesting the same feedback is relevant for the observed event. Finally, conclusions are given in section 7 , with discussion in particular of the implication of these results for efforts to model and forecast the QBO.

\section{Model and data}

\section{a. Model configuration}

The dry dynamical core used is a version of the Reading Intermediate General Circulation Model (IGCM) that solves the hydrostatic primitive equations following Hoskins and Simmons (1975). All integrations are performed using the "jagged" triangular truncation T42 (Hoskins and Simmons 1975) on $N=60$ hybrid pressure levels spanning from the surface to a log-pressure height of $z_{T}=60 \mathrm{~km}$. The angular momentum-conserving vertical discretization of Simmons and Burridge (1981) is used; this is not a standard feature of the IGCM. The hybrid half levels are specified by

$$
\begin{aligned}
\eta_{i+1 / 2} & =\exp \left[-\frac{z_{T}}{H}\left(\frac{i}{N}\right)^{\xi}\right], \quad i=0, . ., N, \quad \xi=1.2, \\
H & =7 \mathrm{~km}
\end{aligned}
$$

and the pressure is specified following Laprise and Girard [1990, their (5.1)] as

$$
\begin{aligned}
& p(\eta)=A(\eta) p_{0}+B(\eta) p_{s}, \\
& A(\eta)=\eta-B(\eta), \\
& B(\eta)=\left(\frac{\eta-\eta_{T}}{1-\eta_{T}}\right)^{r}
\end{aligned}
$$

with $\eta_{T}=\eta_{N+1 / 2}$ and $r=1.5$. The full levels are given by $\eta_{i}=\left(\eta_{i+1 / 2}+\eta_{i-1 / 2}\right) / 2$. This grid has a vertical resolution of about $1 \mathrm{~km}$ in the lower stratosphere and a horizontal resolution of $4.3^{\circ}$ or $480 \mathrm{~km}$.

Explicit sixth-order horizontal hyperdiffusion is used to avoid buildup of enstrophy at small scales. The coefficient is set to $5.27 \times 10^{26} \mathrm{~m}^{6} \mathrm{~s}^{-1}$, corresponding to a damping time scale of 0.25 days for the highest resolved wavenumbers. A Robert time filter with parameter 0.02 is also used.

The diabatic processes are specified following Polvani and Kushner (2002), which produces an extratropical circulation analogous to a perpetual winter configuration, including a stratospheric polar vortex, taken to be in the Northern Hemisphere in the present work. The parameter $\gamma$, which determines the strength of the polar vortex, is set to $1 \mathrm{~K} \mathrm{~km}^{-1}$.

A quasi-stationary wave field is produced by specifying a Gaussian surface topography

$$
h_{s}=h_{0} \exp \left[-\left(\frac{\phi-\phi_{h}}{\Delta \phi_{h}}\right)^{2}-\left(\frac{\lambda}{\Delta \lambda_{h}}\right)^{2}\right],
$$

centered in the Northern Hemisphere at $\phi_{h}=45^{\circ} \mathrm{N}$ with $\Delta \phi_{h}=\Delta \lambda_{h}=15^{\circ}$. The height $h_{0}$ of the mountain is $3 \mathrm{~km}$.

Other parameters (including the surface- and spongelayer friction) are set identically following Polvani and Kushner (2002), with the exception of $\kappa(0.286$ is used here instead of 2/7) and the hemispheric asymmetry parameter $\varepsilon$, set here to $5 \mathrm{~K}$. 
As has been found by other authors, the structure of tropical variability in such configurations is sensitive to subtle details, for example, to the choice of dynamical core (Yao and Jablonowski 2015). This is found to be the case here as well; for instance, varying $\varepsilon$ by just a few degrees is enough to substantially change the character of the easterly jets. We proceed for now assuming that this sensitivity does not imply that the processes involved in the disruption events themselves are similarly sensitive and return to this question briefly in the conclusions.

The base run has been integrated for 25000 days, with instantaneous output every $6 \mathrm{~h}$. A brief description of the behavior was given in section 1 . Further detailed description and interpretation is given in section 3 . Further integrations of the model, with changes in configuration to examine interaction between waves and mean flow, are described in section 5; these produced instantaneous output on a daily basis. All quantities shown are based on daily averages of the 6-h output in the case of the base run or the daily instantaneous output of the further integrations.

\section{b. Reanalysis data}

We make use of 6-hourly model level data output on a $1^{\circ}$ grid from the ERA-Interim (Dee et al. 2011). Quantities shown on pressure levels are interpolated first to the pressure levels closest to the hybridized model levels.

\section{c. Derived fields}

The forcing of the mean flow by the waves is diagnosed using the transformed Eulerian-mean framework (Andrews et al. 1987). The wave forcing is quantified by the E-P flux, while the meridional circulation is estimated by the residual velocities and streamfunction, as defined on log-pressure coordinates following Andrews et al. (1987). The meridional gradient of quasigeostrophic potential vorticity is computed on pressure levels also following Andrews et al. (1987) as

$$
\frac{\partial_{\phi} \bar{q}}{a}=\frac{2 \Omega}{a} \cos \phi-\partial_{\phi}\left[\frac{\partial_{\phi}(\cos \phi \bar{u})}{a^{2} \cos \phi}\right]-\frac{1}{\rho_{0}} \partial_{z}\left(\rho_{0} \frac{f^{2}}{N^{2}} \partial_{z} \bar{u}\right) .
$$

\section{d. Time filtering}

Fields are in some cases smoothed in time by convolving time series with an exponential filter of time scale $\tau$ of the form

$$
f(t ; \tau)=e^{-|t| / \tau} .
$$

The wave forcing is smoothed using a causal version of this filter: $f_{c}(t ; \tau)=e^{-t / \tau} \quad$ if $\quad t \geq 0 \quad$ and $\quad 0 \quad$ otherwise.

This is motivated by the fact that only wave forcing that precedes a given time contributes to the structure of the circulation at that time. In all cases, a finite number of weights are used; this is chosen to be large enough that the results are not sensitive to further increases. The choice of time scale $\tau$ is given in the figure captions.

\section{Phenomenology of the disruptions}

We present in this section further quantitative details of the tropical circulation obtained in the base run, emphasizing the dynamics of the disruptions. Tropical upwelling in this model configuration is on the order of $5 \times 10^{-5} \mathrm{~m} \mathrm{~s}^{-1}$ at $30 \mathrm{hPa}$, or about $1 \mathrm{~km}$ every 230 days. This is substantially weaker than the estimate of observed tropical upwelling, which is roughly $3 \times 10^{-4} \mathrm{~m} \mathrm{~s}^{-1}$ at $70 \mathrm{hPa}$, or about $1 \mathrm{~km}$ every 40 days. Nonetheless, the upwelling plays an important role in the overall structure of the equatorial winds. The westerly equatorial jet arises from the ascent of air through a region of momentum flux convergence; this is primarily due to vertically propagating waves (not shown) but includes a weak contribution from horizontal momentum fluxes (seen in Fig. 1b). The vertically propagating waves are likely Kelvin waves forced nonlinearly through extratropical variability given the absence of any convection (parameterized or otherwise). The momentum flux convergence between 40 and $20 \mathrm{hPa}$ is weak, and winds are therefore approximately uniform with height. Above $20 \mathrm{hPa}$, there is a further region of positive momentum flux convergence, again arising both from horizontally and vertically propagating waves. The easterly jets form within the layer of uniform winds after an extended period of variable but systematically easterly forcing then migrate upward, with weak westerlies then being restored by upward advection from the westerly shear layer at $50 \mathrm{hPa}$.

The structure of the jet and the meridional component of the E-P flux in the meridional plane is shown in Figs. 2a-c for three periods: prior, during, and after the disruption highlighted in Fig. 1b. The central dates of these periods are indicated by vertical dashed lines in Fig. 1a. The westerly winds at the equator are seen to be part of a relatively narrow jet, generally confined to within $15^{\circ}$ of the equator. In all cases, there is southward cross-equatorial E-P flux throughout the tropical stratosphere, consistent with the presence of westerly winds and stationary wave source in the Northern Hemisphere and easterly winds in the Southern Hemisphere, though the convergence of these fluxes is weak. 
(a) $u, F^{\phi}$ day 10500

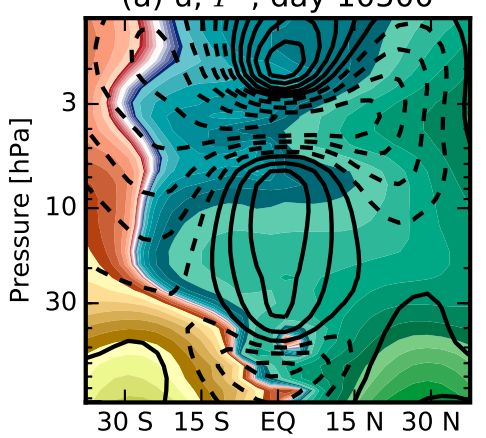

(d) $u, \Psi^{\prime *}$, day 10500

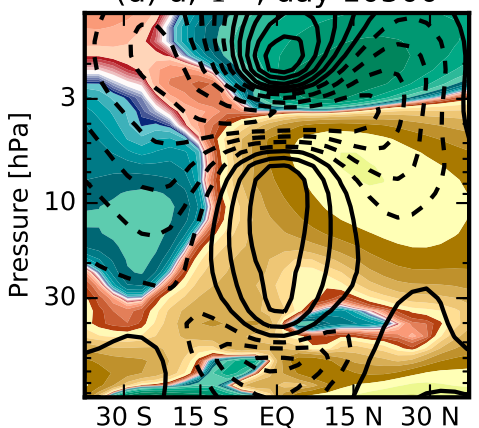

(b) $\mathrm{u}, F^{\phi}$, day 13500

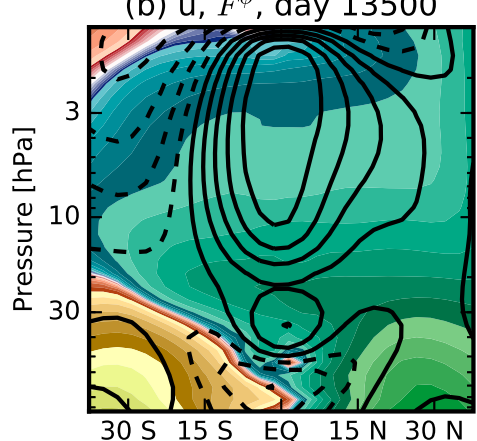

(e) $\mathrm{u}, \Psi^{\prime *}$, day 13500

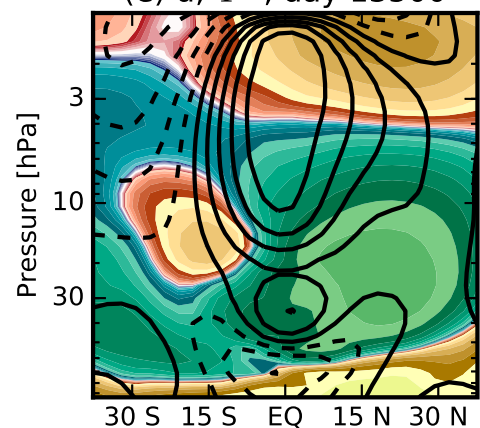

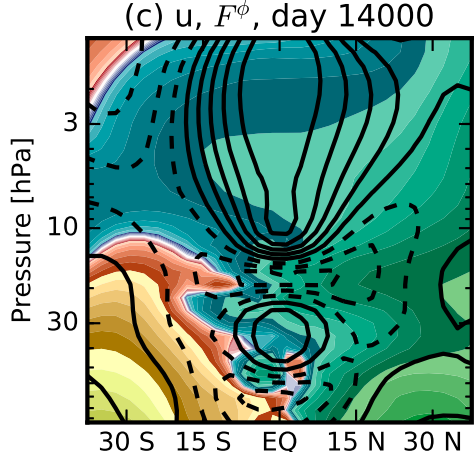

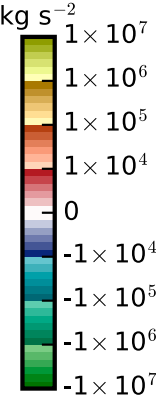

(f) $u, \Psi^{\prime *}$, day 14000

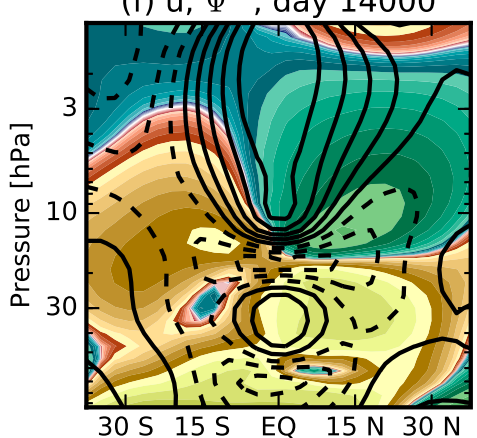

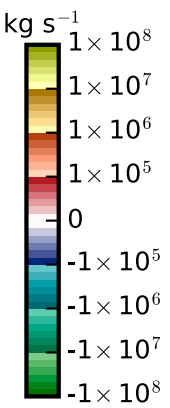

FIG. 2. (a)-(c) Zonal-mean zonal wind (black contours; interval: $5 \mathrm{~m} \mathrm{~s}^{-1}$ ) and meridional component of the E-P flux (shading). (d)-(f) Zonal-mean zonal wind as in (a)-(c) and anomalous residual mass streamfunction (shading). Three times are shown, corresponding to the vertical lines in Fig. 1a: (a),(d) prior to, (b),(e) during, and (c),(f) after the emergence of the easterly jet. The anomalous circulation is clockwise around positive contours of the streamfunction. The zonal winds and streamfunction are smoothed with a 50-day low-pass exponential filter, while the E-P fluxes are smoothed with a causal 50-day low-pass exponential filter.

At day 10500 (Fig. 2a), the easterly jet from previous disruption around day 8000 has reached the upper stratosphere, and the westerly jet that is reforming below does not yet show a strong second shear zone above $30 \mathrm{hPa}$. The cross-equatorial meridional E-P fluxes are somewhat stronger toward the base of the jet. By day 13500 (Fig. 2b), the top westerly jet has reached nearly $1 \mathrm{hPa}$. Although the easterly jet has not yet emerged, the jet has narrowed significantly just below $20 \mathrm{hPa}$. The cross-equatorial fluxes within $10^{\circ}$ of the equator are strongest at this level. The winds at $20 \mathrm{hPa}$ reverse at about day 13650, and by day 14000 (Fig. 2c), the easterly jet has fully formed. In contrast to the tall narrow westerly jet, the easterly jet is shallow and broad. The shear zones above and below the easterly jet are stronger than the shear zone at $50 \mathrm{hPa}$, reaching magnitudes greater than $0.01 \mathrm{~s}^{-1}$ (shear zones associated with the observed QBO approach but rarely exceed this value). Remarkably, the equatorward fluxes are stronger at the level of the easterly jet than they are through the westerly winds above and below, despite the presence of a zero wind line. The same feature can be seen near $5 \mathrm{hPa}$ at the level of the easterly jet around day 10500 (Fig. 2a). The fluxes that are focused on the easterly jet are strongly absorbed by the jet in contrast to the fluxes through the westerly jets, which cross the equator relatively unchanged. It is worth noting that most of the patterns of divergence and convergence seen in Fig. $1 b$ arise from quite subtle features in these cross-equatorial fluxes.

Figures $2 \mathrm{~d}-\mathrm{f}$ show the anomalous residual mass streamfunction (defined with respect to the time average over days 5000-25000). This highlights the presence of secondary circulation cells with vertical convergence and meridional outflow over the equator at the level of the easterly jet, with return flow broadly centered on the westerly jet. The circulations can be understood through the well-established arguments that have previously been applied to the QBO (e.g., Plumb and Bell 1982), that they are maintained by the radiative damping of temperature anomalies associated with vertical shear at the equator, implying relative descent in westerly shear zones and relative ascent in easterly shear zones. Here, the structure of the circulations is consistent with a tendency to make westerly jets tall and narrow and easterly jets shallow and broad.

The evolution of equatorial winds, the full E-P flux divergence, and the vertical velocity composited over five disruption events are shown in further detail in 


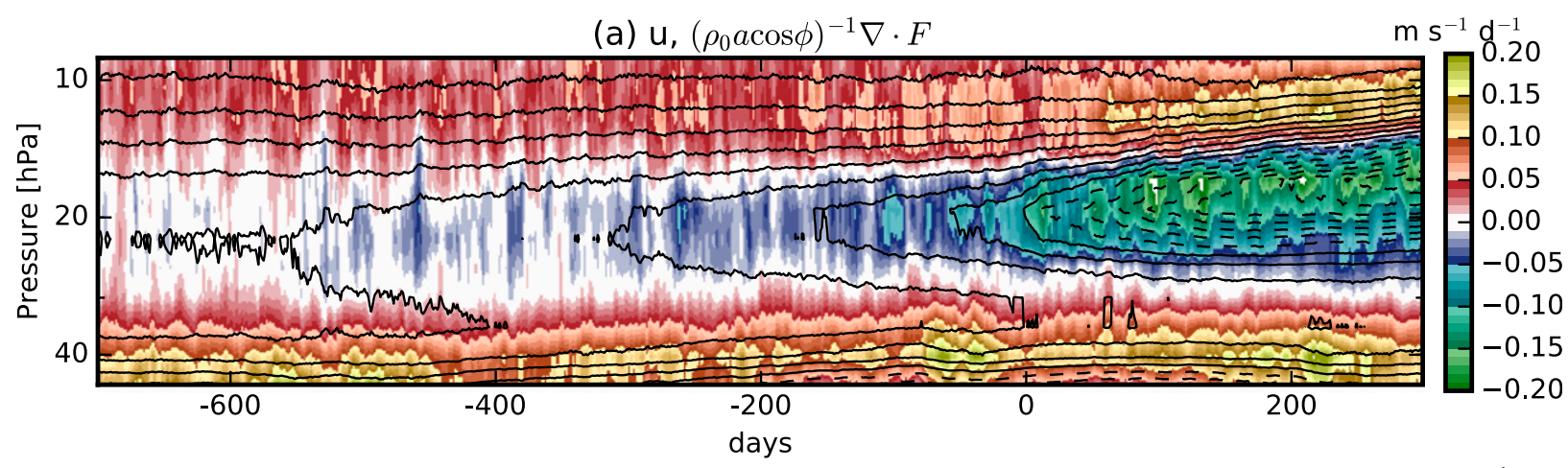

(b) $\mathrm{u}, \bar{w}^{*}$

$\mathrm{mm} \mathrm{s}^{-1}$

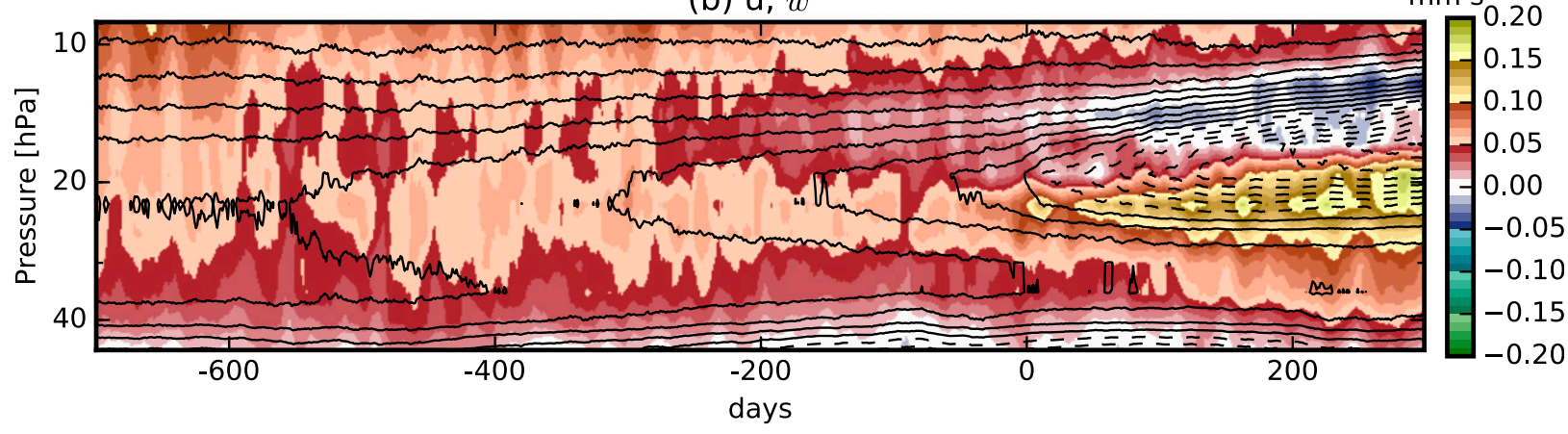

FIG. 3. Composites over the five disruptions shown in Fig. 1, averaged over $5^{\circ} \mathrm{S}-5^{\circ} \mathrm{N}$. (a) Zonal wind (contours; interval: $2 \mathrm{~m} \mathrm{~s}{ }^{-1}$ ) and zonal wind tendency due to the total divergence of the E-P flux (shading). The zonal winds are not smoothed, and the flux divergences are smoothed with a causal 10-day low-pass exponential filter. (b) Zonal winds as in (a) and residual vertical velocity (shading). The latter is smoothed with a 5-day low-pass exponential filter.

Fig. 3. The central date of the disruptions is defined by the date at which the zonal wind first turns easterly at $20 \mathrm{hPa}$. By 500 days prior to the disruption, the net wave driving (Fig. 3a) is weak but systematically easterly over the layer of uniform westerly winds. The wave forcing is dominated by meridional fluxes, but its structure is modified by vertical fluxes as can be inferred by comparing with earlier figures. The layer of easterly forcing is quite shallow and roughly commensurate with the depth of the easterly jet that emerges at the central date. The beginning of a well-defined easterly anomaly arises in the composite 500 days prior to the central date, centered somewhat below the level at which the winds first reverse. The composite wave driving strengthens somewhat over these 500 days, though the wave driving in individual events is still quite intermittent as can be seen in Fig. 1b. Around the central date, the wave driving strengthens substantially as the easterly jet strengthens and begins to migrate upward, consistent with the focusing seen in Fig. 2c.

Prior to the reversal, there is ascent throughout the depth of the tropical stratosphere (Fig. 3b). As the westerly shear strengthens, the secondary circulation first counteracts and then ultimately overwhelms the background upwelling, resulting in net downwelling on the upper flank of the easterly jet. Conversely, the ascent strengthens in the easterly shear zone. Consistent with the discussion of the streamfunction anomalies shown in Fig. 2, the secondary circulation acts in the vertical to confine the easterly jet and extend the westerly jet.

We have deliberately avoided presenting the momentum budget during this period, in part to avoid a lengthy digression on the technical details and in part because closing the budget accurately in this region is quite difficult given the delicate balances and short vertical length scales relative to the model grid spacing. It has been confirmed, however, that the easterly wave forcing associated with the meridional E-P flux convergence is the dominant easterly force and is more than sufficient to explain the net acceleration over the period shown in Fig. 3.

\section{Response of a vertical advection model}

To better understand this phenomenology, we consider first the role of advection by the secondary circulation in the response of the westerly jet to an applied force. The basic model we will use is a one-dimensional model of the vertical profile of equatorial zonal-mean zonal wind $u(z, t)$, considering explicitly the role of vertical advection 


$$
\partial_{t} u+\left(w_{0}-\Gamma \partial_{z} u\right) \partial_{z} u=\mathscr{F} .
$$

We include an applied force $\mathscr{F}$ to represent the easterly wave force over the 500 days or so prior to the onset of the easterly winds; we will focus mostly on the case where $\mathscr{F}$ is negative and constant in time. We return to the substantial enhancement of the wave forcing after this period in the next section.

The zonal wind is advected by the vertical wind that consists of a constant background upwelling $w_{0}>0$ modulated by the secondary circulation produced by radiative relaxation $\left(-\Gamma \partial_{z} u\right)$. This sensitivity of the vertical winds to the vertical shear and its role in the descent of QBO winds in the meridional plane is discussed by Dunkerton (1991). We restrict our attention here to a single (spatial) dimension for simplicity, though this has an apparent price: (9) does not conserve total momentum $\int u d z$. This is in fact consistent with considering this to be a model of the equatorial region under some simple assumptions as justified in appendix A; the lack of conservation can be associated with an implied meridional transport and is in fact a useful feature of (9), as will become apparent. The essential mechanisms discussed here have also been confirmed in a zonally symmetric model of the meridional plane (not shown).

After Dunkerton (1991, his section 4), $\Gamma$ can be related to other known parameters. Consider a local temperature anomaly $T^{\prime}$ with meridional length scale $L$ over the equator:

$$
T^{\prime}=T_{0}\left(1-\frac{y^{2}}{2 L^{2}}\right)
$$

Assuming thermal wind balance $\beta y \partial_{z} u=-R \partial_{y} T^{\prime} / H$ and that the relaxational radiative heating is in quasi-steady balance with the adiabatic heating $N^{2} w^{\prime}=-\alpha R T^{\prime} / H$, then at the equator, $\Gamma=\alpha \beta L^{2} / N^{2}$. Here, $\alpha$ is the radiative relaxation rate, $\beta$ is the meridional gradient of the Coriolis parameter at the equator, $N$ is the buoyancy frequency, $R$ is the dry gas constant, and $H$ is a densityscale height.

\section{a. Steady-state response}

Returning to (9), it is useful to consider first the steady-state solution to a fixed imposed forcing $\mathscr{T}=f(z)$. There are two solutions for the shear as a result of the quadratic nonlinearity:

$$
\partial_{z} u=\frac{w_{0}}{2 \Gamma}\left[1 \pm \sqrt{1-\frac{4 \Gamma f(z)}{w_{0}^{2}}}\right] .
$$

If the secondary circulation is weak compared to the background upwelling, the appropriate solution is the negative root. For small values of the nondimensional forcing $\Gamma f(z) / w_{0}^{2}$, this solution can be written as

$$
\begin{gathered}
\partial_{z} u=\frac{f}{w_{0}}+\frac{\Gamma f^{2}}{w_{0}^{3}}+O\left\{\left[\frac{\Gamma f(z)}{w_{0}^{2}}\right]^{2}\right\}, \\
u(z) \approx u\left(z_{0}\right)+\int_{0}^{z} \frac{f\left(z^{\prime}\right)}{w_{0}}+\frac{\Gamma f\left(z^{\prime}\right)^{2}}{w_{0}^{3}} d z^{\prime},
\end{gathered}
$$

where (13) follows if the origin is taken to be below a localized forcing. For a single-signed forcing, the largest response is above the forcing region where the ascending parcels have been subject to the largest timeintegrated force. In the presence of stronger upwelling, parcels will be subject to the forcing for a shorter time; therefore, the net zonal wind response will be weaker. Steady state is achieved by advecting the anomalous momentum upward away from the region of the forcing.

The secondary circulation introduces an asymmetry between westerly and easterly forces. The ascent of parcels through an easterly force increases, shortening their residence time and weakening the wind response. In this case, (11) remains valid, though for large forcings, the shear depends on the square root of the forcing (instead of linearly in the case with $\Gamma=0$ ). In contrast, the ascent of parcels through a westerly force will slow, lengthening their residence time within the forcing region and resulting in an amplified wind response at the top of the jet. If the forcing exceeds the threshold $w_{0}^{2} / 4 \Gamma$ at some height $z$, the steady-state solution in (11) is no longer valid.

\section{b. Response to a switch-on forcing}

More direct insight comes from analysis of the transient problem in which $u$ is initially zero. We consider again a localized force, with vertical length scale $D=z_{f}$, but assume in this subsection that it is abruptly switched on then held fixed. On time scales that are short relative to the advective time scale $T=z_{f} / w_{0}$, easterly shear will develop where the easterly forcing amplitude increases with height and westerly shear where the easterly forcing amplitude decreases with height. The ascent of parcels within the westerly shear zone will slow, and for sufficiently strong forcing, the induced secondary circulation will produce net downwelling. It is shown in appendix B that if the easterly forcing is stronger than

$$
F_{c}=\frac{w_{0}^{2}}{4 \Gamma}=\frac{w_{0}^{2} N^{2}}{4 \alpha \beta L^{2}},
$$

this process leads in (9) to the formation of a localized easterly jet with a discontinuity in the shear at the jet 


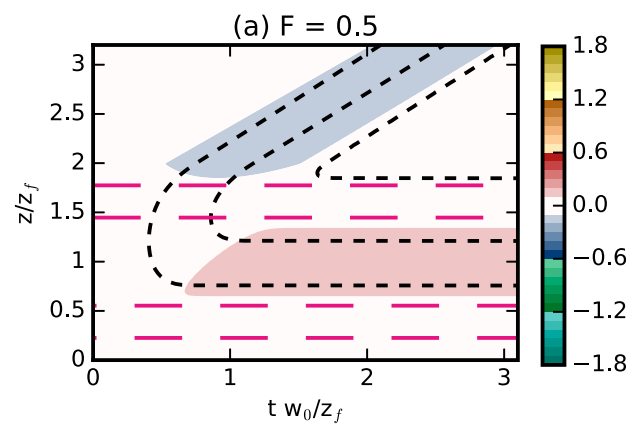

(b) $\mathrm{F}=2$

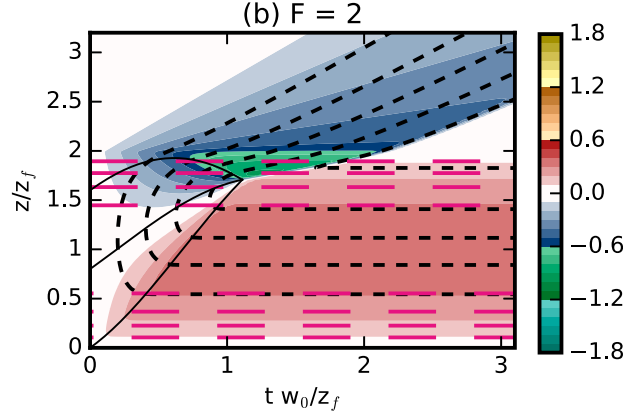

(c) $\mathrm{F}=8$

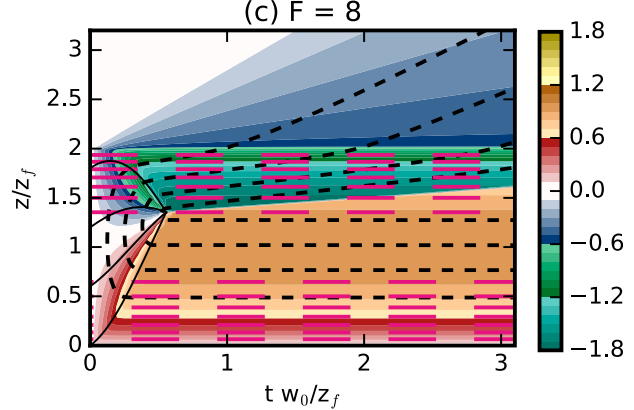

FIG. 4. Nondimensional zonal winds (dashed black contours), forcing (dashed magenta contours), and secondary vertical winds (shading) for three values of the nondimensional forcing $F$ : (a) 0.5 , (b) 2 , and (c) 8 . The contour interval for the both the zonal winds and the forcing are $0.1,0.2$, and 0.5 in the respective panels. The trajectories of several characteristics are shown in (b) and (c), which converge at the formation of the cusp (solid lines; see appendix B for details).

maximum. From the discussion of the steady-state solution in the previous section, one might assume that the arresting of parcel ascent would lead to the buildup of easterly momentum within the forcing region; that this does not occur is a result of the meridional transport implied by (9).

It is worth noting that this threshold does not depend on the vertical length scale of the force; though for fixed $f_{c}, w_{0}$, and $\Gamma$, the time scale on which this localized maximum emerges, and the magnitude of the associated wind anomalies, do.

This is illustrated in Fig. 4, which shows numerical solutions to (9) for a forcing:

$$
\begin{aligned}
& f(z)=-\frac{f_{0}}{z_{f}^{2}}\left(2 z_{f}-z\right) z \text { if } 0<z<2 z_{f} \\
& \text { and } 0 \text { otherwise, }
\end{aligned}
$$

with three values of $f_{0}$. The flow has been nondimensionalized using the advective time scale $T$, the vertical scale $D$ of the forcing, and a velocity scale $U=w_{0} z_{f} / 2 \Gamma$. The last scale can be thought of as the wind anomaly associated with a shear layer strong enough for the secondary circulation to be comparable to the background upwelling, with a factor of 2 included for analytical convenience. The solution is determined by the single nondimensional parameter $F=f_{0} / F_{c}$. Weak vertical diffusion has been added to keep the solutions regular, but it has been verified that the character of the solutions is very weakly sensitive to the value chosen.

Figure 4a shows the solution for $F=0.5$. The shading shows the secondary vertical winds, normalized by the background upwelling $w_{0}$. The upwelling is only slightly enhanced through the forcing layer where forcing produces easterly shear, and the region of transient westerly shear is advected away as the easterly anomaly spreads upward.

Figure $4 \mathrm{~b}$ shows the case $F=2$. In this case, the secondary circulation is of the same order as the background upwelling, although no net downwelling is produced (values remain below 1). Nonetheless, the vertical convergence is still sufficient to form a localized easterly jet (with a discontinuity in the shear in the inviscid case, as indicated by the characteristics-see appendix B for discussion). The jet maximum forms within the forcing layer but above its midpoint then migrates upward until it reaches the top of the forcing layer, upon which the easterly winds again spread upward.

For stronger values of the forcing (Fig. 4c), net downwelling is produced over a narrow region, as occurs in the composite (Fig. 3b). The jet maximum forms earlier and closer to the midpoint of the forcing layer and persists within the forcing region for a longer period of time. The magnitude of the westerly shear above the jet core is stronger than the easterly shear below, also consistent with Fig. 3.

Despite the fact that parcels are being advected toward the center of the jet from above and below, implying they can remain in the forcing region indefinitely, the easterly winds strengthen only moderately. The convergence of the vertical velocities implies a meridional divergence and thus that the easterly momentum is being transported off the equator, consistent with the structure of the secondary circulation and shallow, broad aspect ratio of the easterly jets seen in Fig. 2. 
(a) $h_{0}=1500 \mathrm{~m}$

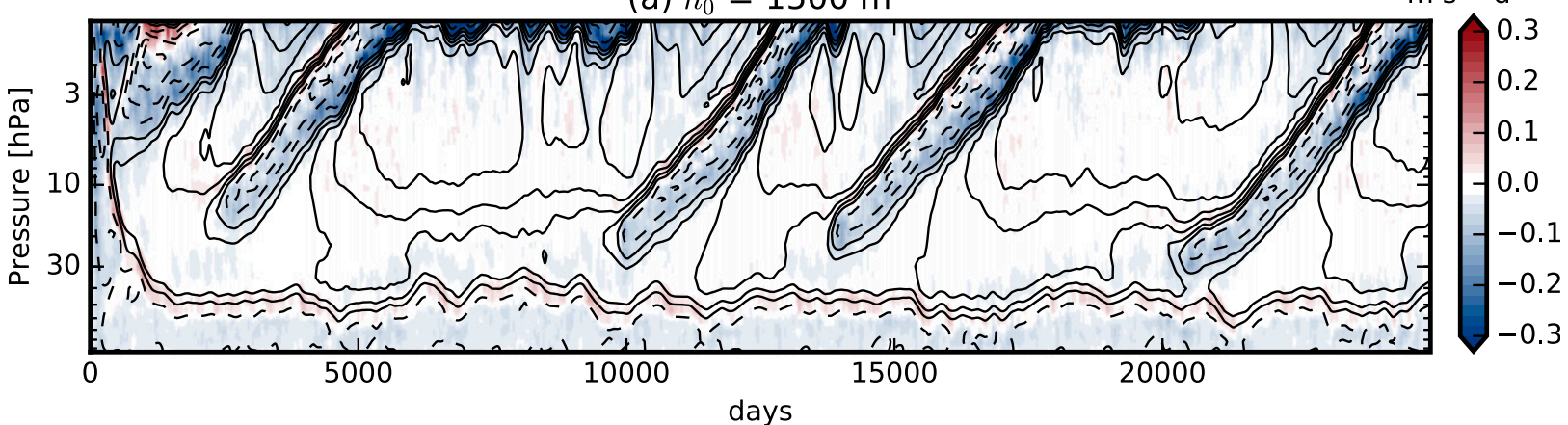

(b) $h_{0}=1000 \mathrm{~m}$ $\mathrm{m} \mathrm{s}^{-1} \mathrm{~d}^{-1}$

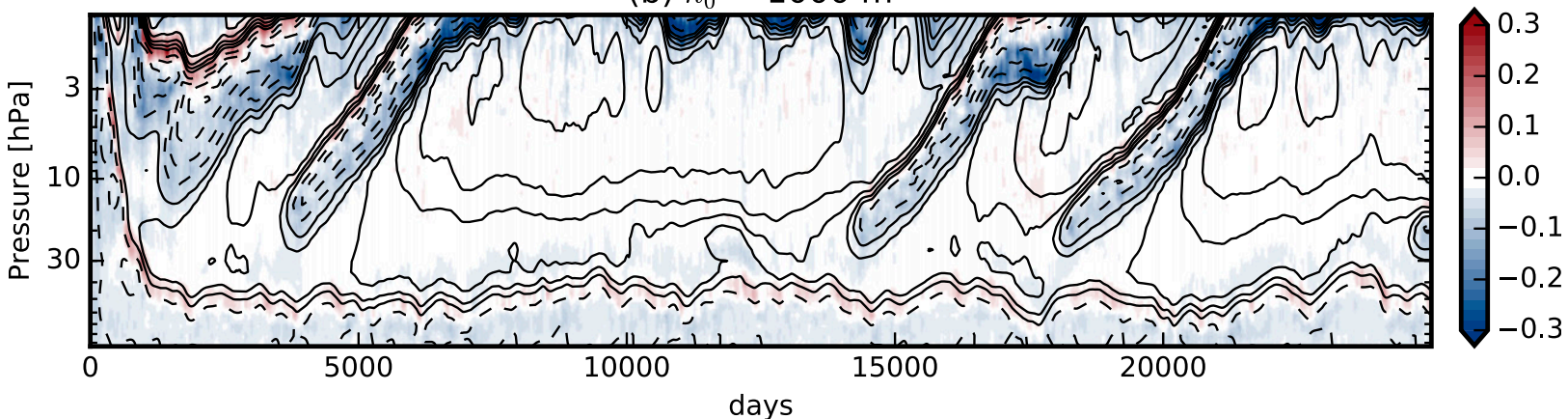

(c) $h_{0}=500 \mathrm{~m}$

$\mathrm{m} \mathrm{s}^{-1} \mathrm{~d}^{-1}$

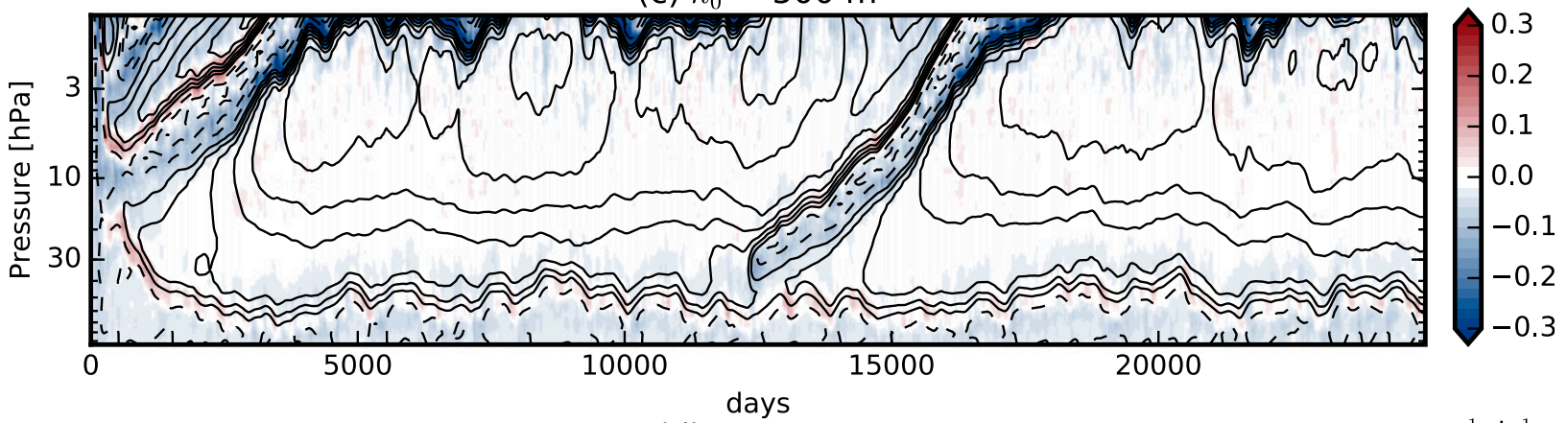

(d) $h_{0}=0 \mathrm{~m}$

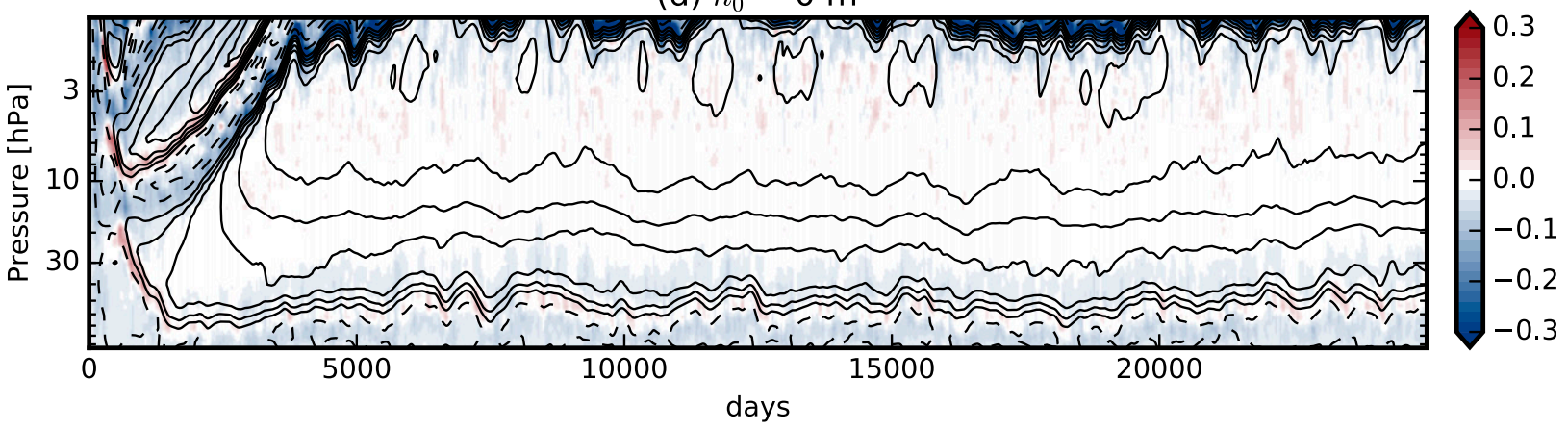

FIG. 5. As in Fig. 1a, but for various heights of the topographic forcing.

This simple advective model provides the following predictions. First, it suggests a threshold, $F=1$, above which an imposed easterly forcing will produce an isolated easterly jet within the forcing layer that spreads meridionally (at least transiently), as opposed to an easterly anomaly that spreads upward with the largest response above the layer of the forcing. It can be shown that this threshold applies essentially unchanged to an applied force of any given vertical structure and can be generalized to the case where there is shear in the initial 
profile; these arguments are given in appendix B. Second, for all values of $F$, the maximum wind response is above the center of the forcing layer, suggesting that the forcing relevant to the disruption lies below the level at which the jets form.

While the secondary circulation is essential for determining the aspect ratio of the jet, the vertical scale is determined by the imposed forcing. This is consistent with the structure of the wave driving shown in Fig. 3a and will be discussed in the context of the observed disruption in section 6 .

\section{A positive wave-mean flow feedback}

\section{a. Sensitivity to the stationary wave field}

With these insights from the one-dimensional advective model in hand, we return now to the disruptions in the dry dynamical core. It will prove useful to have a basic state in which the tall westerly jet is not spontaneously disrupted by the internal dynamics of the model; easterly forcings of a given geometry can then be externally imposed to test the behavior expected from the previous section. This, fortuitously, can be achieved by reducing and ultimately eliminating the surface topography in the Northern Hemisphere, though we note that there is still a substantial extratropical planetary-scale wave field even in the absence of the surface topography, forced by nonlinear effects (Scinocca and Haynes 1998).

Figure 5 shows panels equivalent to Fig. 1a for four additional runs with the height $h_{0}$ of the surface topography [cf. (5)] reduced to $1500,1000,500$, and finally $0 \mathrm{~m}$. The number of disruptions in each successive run is reduced from (respectively) four to three to one and finally to zero disruptions within the 25000 -day integration after the initial transient period. The period between disruptions remains highly variable; in both the $h_{0}=1500$ and $1000 \mathrm{~m}$ runs, there are disruptions that occur within 4000 days of each other, comparable to the shortest interval between disruptions seen in the base run. The maximum acceleration attained when the winds do reverse from westerly to easterly is very similar across the reduced topography runs and the base run. These features again suggest that while there is a strongly stochastic aspect to the initiation of the disruptions that depends on $h_{0}$, the development of the easterly jet itself is controlled by a deterministic feedback that does not. The presence of such a feedback will shortly be confirmed.

\section{b. Imposed forcing}

The predictions of the previous sections can now be tested directly by spinning off a further set of 20-member ensembles from the $h_{0}=0$-m integration in which a zonally symmetric force $G$ is imposed. After some trial and error, it was found that considering an ensemble and separating the starting dates by 1000 days were necessary to avoid artifacts due to lowfrequency variability in the westerly shear zone near $50 \mathrm{hPa}$. The imposed force is chosen to resemble the composite structure of the wave driving seen prior to the onset of the easterly forcing in Fig. 3a and has the structure

$$
G(\phi, z)=f_{0} \exp \left(-\frac{\phi^{2}}{2 \Delta \phi_{f}}\right) \min \left[1-\left(\frac{z-z_{f}}{\Delta z_{f}}\right)^{2}, 0\right]
$$

with $\Delta \phi_{f}=10^{\circ}, z_{f}=27.1 \mathrm{~km}$, and $\Delta z_{f}=1.2 \mathrm{~km}$. It is switched on immediately at the onset of the run. Three ensembles are considered, f8, f15, and $\mathrm{f} 30$, with respective values for $f_{0}$ of $8 \times 10^{-3}, 15 \times 10^{-3}$, and $30 \times 10^{-3} \mathrm{~m} \mathrm{~s}^{-1} \mathrm{day}^{-1}$. The composite easterly force (Fig. 3a) lies somewhere between the case $\mathrm{f} 15$ and $\mathrm{f} 30$.

Before discussing the responses, it is worth estimating from (14) the magnitude of the threshold force $F_{c}$. The equatorial value of $\beta$ and the radiative damping rate are specified externally in the dry dynamical core; $\beta$ is $2.3 \times 10^{-11} \mathrm{~m}^{-1} \mathrm{~s}^{-1}$, and $\alpha$ is $2.9 \times 10^{-7} \mathrm{~s}^{-1}$. Assuming the length scale of the temperature response will be that of the forcing, $L$ is about $7.8 \times 10^{5} \mathrm{~m}$. The buoyancy frequency in this region is essentially determined by the imposed radiative equilibrium temperature and is very close to $2.1 \times 10^{-2} \mathrm{~s}^{-1}$. This gives a value of $\Gamma$ close to $0.01 \mathrm{~m}$. The tropical upwelling in the run with no topography is somewhat weaker than that in the base run; at the levels of the imposed force, a value of $3.0 \times 10^{-5} \mathrm{~m} \mathrm{~s}^{-1}$ is a reasonable estimate. The critical forcing $F_{c}$ is then about $2.0 \times 10^{-3} \mathrm{~m} \mathrm{~s}^{-1} \mathrm{day}^{-1}$. Each of the imposed forcings considered is therefore well within the strong forcing regime, so in the absence of significant eddy responses, we expect the vertical scale of the jet response to match that of the imposed forcing. For comparison with the advective model, the advective time scale $T$ is about 600 days, and the characteristic shear $U / z_{f}$ is about $0.0015 \mathrm{~s}^{-1}$.

The anomalous zonal-mean zonal wind, wave forcing, and residual vertical velocities, computed with respect to the corresponding period in the unperturbed no-topography run, are shown in Fig. 6 for the three ensembles. The two weaker cases, $\mathrm{f} 8$ and $\mathrm{f} 15$, produce a weak easterly anomaly centered on the level of the imposed forcing with a comparable vertical length scale. The wind response is roughly linear in the strength of the forcing, reaching by the end of 

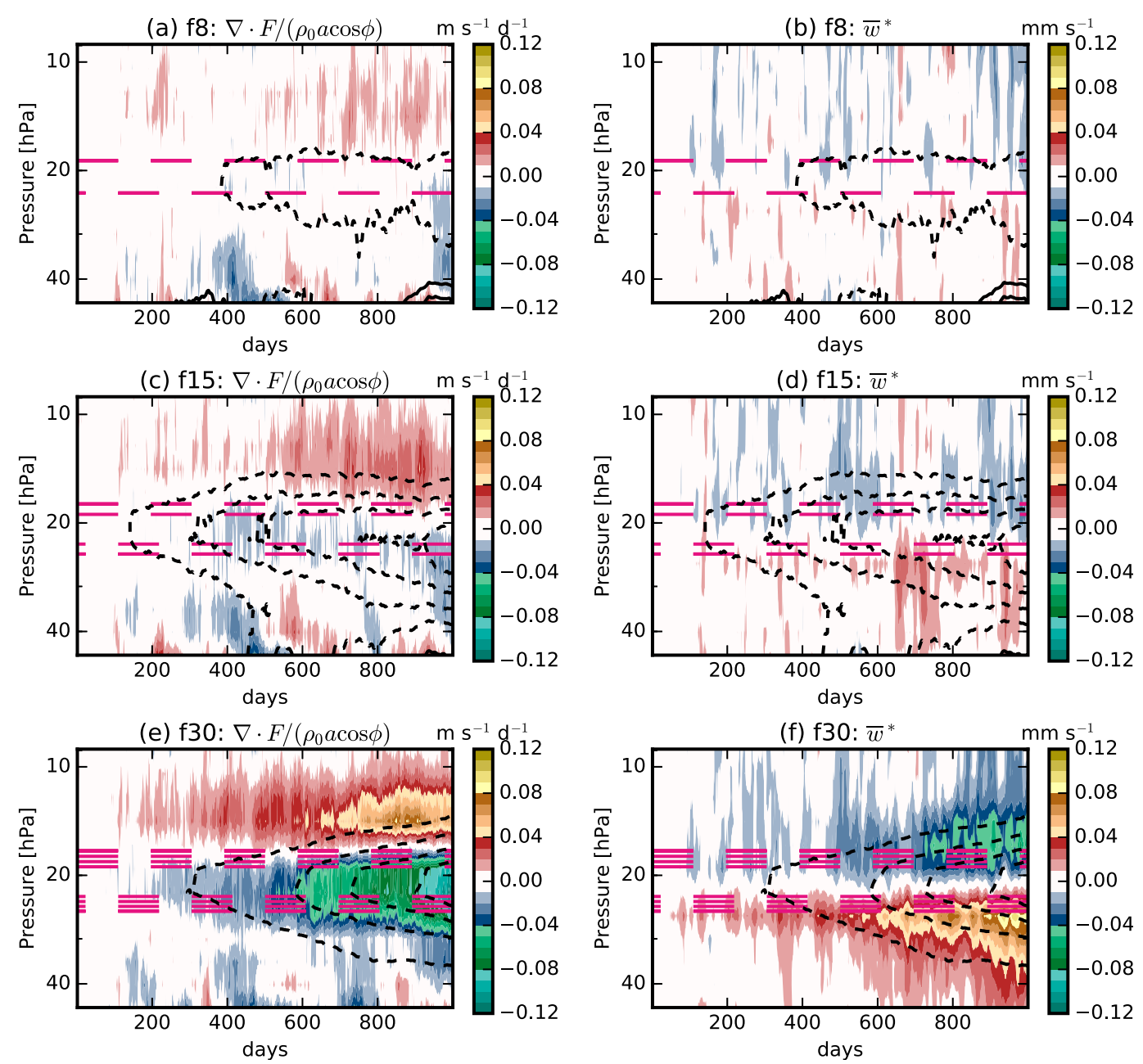

FIG. 6. Ensemble-averaged anomalous (a)-(f) equatorial zonal-mean zonal winds, (a),(c),(e) wind tendency due to the E-P flux divergence, and (b),(d),(f) residual vertical velocity averaged over $5^{\circ} \mathrm{S}-5^{\circ} \mathrm{N}$ for three successively stronger imposed easterly forcings. The zonal winds are smoothed with a low-pass 2-day exponential filter and are indicated by the black contours, with intervals of $1 \mathrm{~m} \mathrm{~s}^{-1}$ in (a)-(d) and $4 \mathrm{~m} \mathrm{~s}^{-1}$ in (e) and (f). The flux divergence is smoothed by a causal 20-day low-pass exponential filter, and the vertical velocities are smoothed with a 20-day lowpass exponential filter. Both are indicated by shading. In all panels, the imposed forcing is indicated by the dashed magenta contours (interval: $5 \times 10^{-3} \mathrm{~m} \mathrm{~s}^{-1}$ day $^{-1}$ ).

the 1000-day integration about $1 \mathrm{~m} \mathrm{~s}^{-1}$ in $\mathrm{f} 8$ and about $3 \mathrm{~m} \mathrm{~s}^{-1}$ in $\mathrm{f} 15$. The response of the eddy forcing in the model at the level of the imposed force is weak in both cases. In contrast, by about 500 days into f30, the eddies are reorganized to produce a strong easterly forcing, amplifying the effects of the imposed force. As a result, by the end of the 1000-day integration, the easterly anomaly reaches about $20 \mathrm{~m} \mathrm{~s}^{-1}$, comparable to the anomaly associated with the disruptions in the base run (cf. Fig. 3). Note that the contour interval for the zonal winds is different for $\mathrm{f} 30$ than for $\mathrm{f} 15$ and $\mathrm{f} 8$, and that, on the color scale used for the eddy forcing, the imposed forcing of $\mathrm{f} 30$ would only just be visible. The fact that a substantial eddy response is seen in f30 but not in $\mathrm{f} 8$ or $\mathrm{f} 15$ suggests the existence of a threshold value for the wind response for this eddy response; this is consistent with the easterly wave driving in Fig. 3a amplifying only once the wind anomaly has reached $6-8 \mathrm{~m} \mathrm{~s}^{-1}$ (it is plausible that this feedback could ultimately arise in $\mathrm{f} 8$ or $\mathrm{f} 15$ if the integrations were carried on for sufficiently long; this has not been explored).

The scaling discussed above suggests that in each case, the secondary circulation should substantially perturb the background upwelling. In the strongest forcing case, f30, this can be seen (Fig. 6f); the strength of the circulation relative to the shear is consistent with the estimated value of $\Gamma$. The secondary circulation 
(a) wj10: $u, F^{(\phi)}$

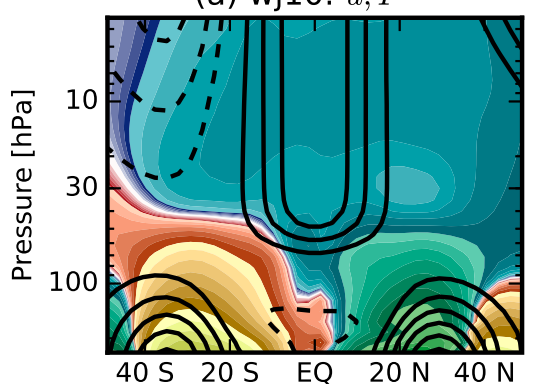

(d) wj10: $\Delta u, a^{-1} \partial_{\phi} q$

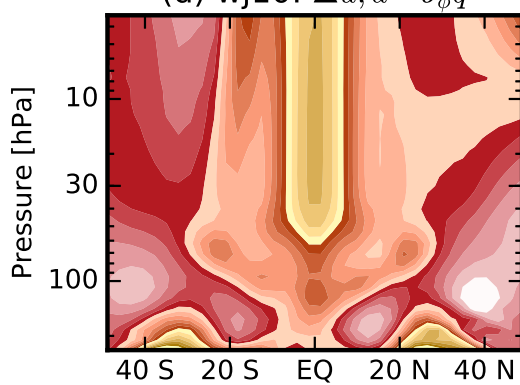

(b) $\mathrm{e} 1: u, \Delta F^{(\phi)}$
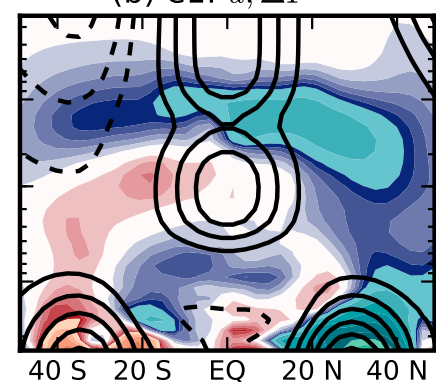

(e) e1: $\Delta u, a^{-1} \partial_{\phi} q$

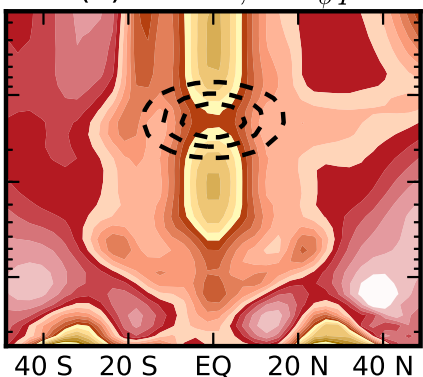

(c) e2: $u, \Delta F^{(\phi)}$

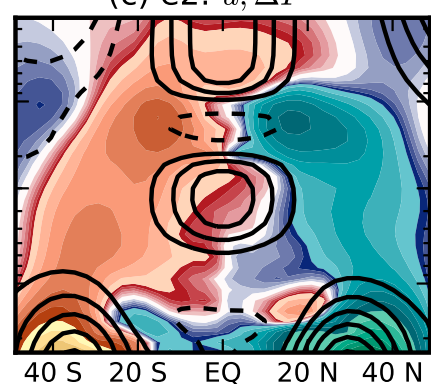

(f) e2: $\Delta u, a^{-1} \partial_{\phi} q$

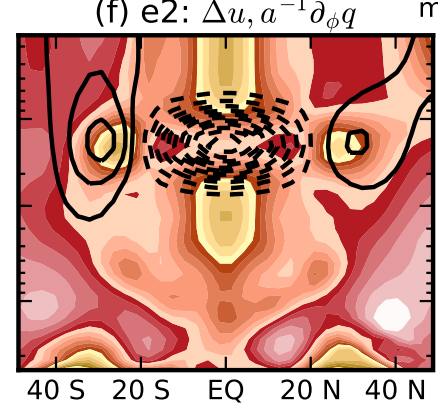

$\mathrm{kg} \mathrm{s}^{-2} 1 \times 10^{8}$

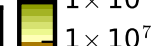

$-\begin{aligned} & 1 \times 10^{7} \\ & 1 \times 10^{6}\end{aligned}$

$1 \times 10^{5}$

$1 \times 10^{5}$

$1 \times 10^{6}$

$-1 \times 10^{7}$

$-1 \times 10^{8}$

FIG. 7. (a) Time-averaged zonal-mean zonal wind (contours; interval: $5 \mathrm{~m} \mathrm{~s}^{-1}$ ) and meridional component of the E-P flux (shading) for the base nudging run. (b),(c) Zonal wind as in (a) and anomalous meridional component of the E-P flux for the two perturbed nudging runs, e1 and e2. (d)-(f) Zonal-mean zonal wind anomaly from the base nudged run (contours; interval: $2.5 \mathrm{~m} \mathrm{~s}^{-1}$ ) and meridional gradient of the quasigeostrophic potential vorticity (shading) for the base nudging run and the two perturbed nudging runs.

response in Figs. 6b,d is also apparent but is subject to considerable noise.

The essential features of the response described by the one-dimensional advective model are therefore confirmed in the dry dynamical core. Moreover, these experiments verify the presence of a dynamical feedback in which the eddy forcing is reorganized to strongly amplify the applied force if the latter is sufficiently strong. Unlike the initiation of the disruptions (which do not occur in the $h_{0}=0$ case), this feedback is active even in the absence of surface topography.

\section{c. Nudged jet structures}

To further explore the nature of this dynamical feedback, additional integrations are performed in which the equatorial zonal mean zonal winds are relaxed, or "nudged," toward a specified profile, allowing the extratropics and the eddies to evolve freely. This approach has been used to artificially produce QBO winds in comprehensive models (e.g., Giorgetta et al. 1999; Marsh et al. 2013).

Three configurations are considered: a reference case and two cases with perturbed profiles. In each case, the model is integrated for 25000 days, and averages are computed from day 2000 to day 25000 . In the reference run $\mathrm{wj}$, the winds are relaxed toward a tall equatorial westerly jet, with fixed meridional curvature throughout the depth of the stratosphere. Surface topography remains absent $\left(h_{0}=0\right)$.

The nudging is imposed as a linear relaxation of the form $-\kappa\left(u-u_{n}\right)$ imposed on the zonal-mean component of the zonal winds:

$$
\begin{aligned}
& \kappa(\phi, z)=\kappa_{0} Z\left(z ; z_{n}^{b}, z_{n}^{t}, \Delta z_{n}\right) \exp \left[1-\frac{1}{1-\left(\phi / \Delta \phi_{n}\right)^{6}}\right] \\
& \text { if } \quad|\phi|<\Delta \phi_{n} \text { and } 0 \quad \text { otherwise, } \\
& u_{n}(\phi, z)=U_{0} Z\left(z ; z_{u}^{b}, z_{u}^{t}, \Delta z_{u}\right) \exp \left(-\frac{\phi^{2}}{2 \Delta \phi_{u}^{2}}\right), \\
& Z\left(z ; z_{b}, z_{t}, \Delta z\right)=\frac{1}{2}\left[\tanh \left(\frac{z-z_{b}}{\Delta z}\right)-\tanh \left(\frac{z-z_{t}}{\Delta z}\right)\right] .
\end{aligned}
$$

The overall time scale of the nudging is $\kappa_{0}^{-1}=1$ day, and parameters dictating the shape of the nudging region are $z_{n}^{b}=18 \mathrm{~km}, z_{n}^{t}=50 \mathrm{~km}, \Delta z_{n}=2 \mathrm{~km}$, and $\Delta \phi_{n}=20^{\circ}$. The reference jet has a maximum speed of $U_{0}=20 \mathrm{~m} \mathrm{~s}^{-1}$, and the shape of the jet is determined by $z_{u}^{b}=20 \mathrm{~km}$, $z_{u}^{t}=50 \mathrm{~km}, \Delta z_{u}=2 \mathrm{~km}$, and $\Delta \phi_{u}=10^{\circ}$.

The resulting winds are shown in Fig. 7a, along with the meridional component of the E-P flux. Despite the lack of surface topography, the westerly winds in the Northern Hemisphere allow waves to propagate upward 

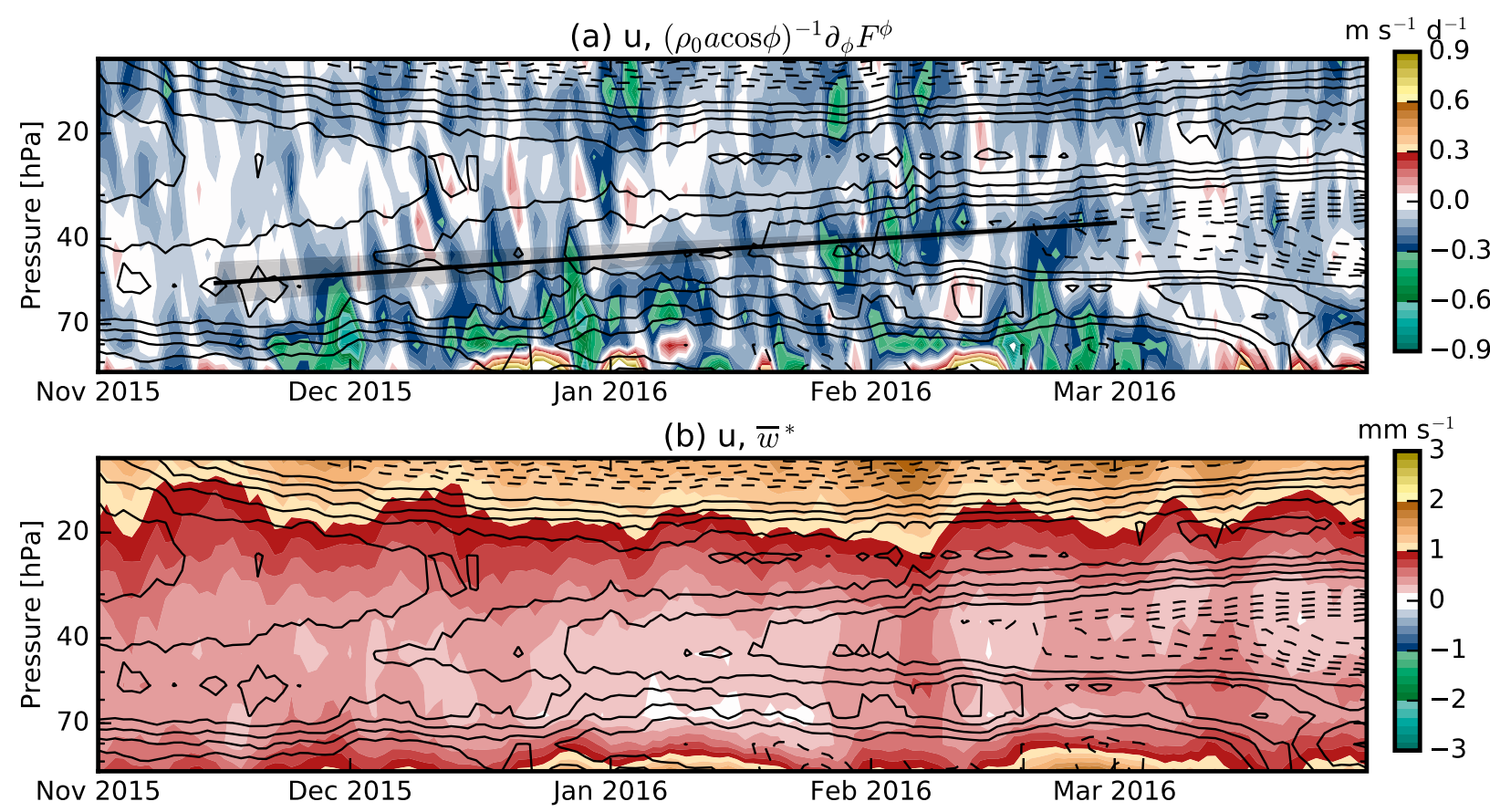

FIG. 8. (a) Zonal-mean zonal winds (contours; interval: $2 \mathrm{~m} \mathrm{~s}^{-1}$ ) and wind tendency due to the meridional divergence of the meridional component of the E-P flux (shading). The black line gives a rough visual estimate of the rate of mean tropical ascent (see text for details). (b) Zonal winds as in (a) and residual vertical velocities (shading). All fields are averaged over $5^{\circ} \mathrm{S}-5^{\circ} \mathrm{N}$. The zonal winds are unsmoothed, the flux divergences are smoothed with a causal 2-day low-pass exponential filter, and the vertical winds are smoothed with a 2-day lowpass exponential filter.

into the stratosphere and then equatorward. The equatorial fluxes are therefore southward and are relatively constant with height within the equatorial westerly jet. The westerly jet is associated with enhanced meridional potential vorticity (PV) gradients along the equator (Fig. 7d).

The wind profile is then perturbed in two further cases, e1 and e2, by introducing a shallow easterly anomaly, centered near $20 \mathrm{hPa}$ (the height at which the jets emerge in the free-running model). This is done by replacing the vertical profile $Z$ of the reference jet by

$$
\tilde{Z}=Z\left\{1-\delta \exp \left[-\frac{\left(z-z_{e}\right)^{2}}{2 \Delta z_{e}^{2}}\right]\right\},
$$

where $z_{e}=30 \mathrm{~km}$ and $\Delta z_{e}=2 \mathrm{~km}$. The anomaly in e1 is half the amplitude of the westerly jet $(\delta=0.5)$, so the winds remain westerly at all heights, while the anomaly in e2 is strong enough to generate an easterly anomaly $(\delta=1.5)$.

Consistent with Fig. 6e, a wind anomaly of $8 \mathrm{~m} \mathrm{~s}^{-1}$ is sufficient to produce a substantial reorganization of the wave fluxes. Figure $7 \mathrm{~b}$ shows the winds in e1, as well as the anomalous meridional E-P fluxes relative to the reference run. The cross-equatorial flux is enhanced by about $40 \%$ in a shallow layer centered at the level of the easterly anomaly. Most of this additional flux is absorbed at the equator. This structure closely resembles that seen in Fig. 2. The wave fluxes in e2 are modified through much of the extratropics. There is a strong local enhancement of flux focused on the easterly jet from both hemispheres (Fig. 7c); these anomalies connect to the upper flanks of the tropospheric subtropical jet, indicating that the easterly anomaly has a substantially nonlocal effect on the eddies. There are corresponding anomalies in the vertical fluxes as well (not shown).

Given the presence of the broad layer of crossequatorial fluxes present in the base run, it is plausible that the presence of an easterly anomaly within the westerly jet can act as a favorable place for wave breaking and the absorption of easterly momentum. The weaker winds imply slower group velocities and thus, for a given flux, larger wave activities that may be more subject to breaking or damping. This mechanism has been invoked in a barotropic context to argue that Rossby waves incident on an easterly anomaly larger than one-fifth of the value of the initial westerly flow would ultimately lead to a wind reversal (Fyfe and Held 1990). The one-fifth value is roughly consistent with the simulations shown in Fig. 6. However, Rossby waves with phase speeds that 
would be expected to break on the equatorial anomaly should be unable to propagate through the much weaker winds in the subtropics (O'Sullivan 1997). Moreover, these arguments do not explain why the fluxes are enhanced throughout a broad region of the subtropics, remote from the region of the imposed anomaly.

The meridional gradients of quasigeostrophic potential vorticity, shown in Figs. $7 \mathrm{~d}-\mathrm{f}$, remain positive throughout the domain and therefore do not suggest that these additional fluxes are generated by barotropic or baroclinic instability. Instead, the region of enhanced PV gradients on the subtropical flanks of the easterly anomaly may be acting as kind of "lightning rod," promoting wave propagation from the upper troposphere and focusing waves toward the developing easterly anomaly, which would, in the absence of such a structure, propagate more diffusely.

The results and discussion of the previous sections suggest that the easterly disruptions in the dry dynamical core are produced in two stages. In the first stage, meridionally propagating eddies produce an initial shallow easterly anomaly. The time required for this is subject to considerable fluctuations, leading to the variable period between disruptions. The second stage begins once this easterly anomaly becomes sufficiently strong, at which point the wave-mean flow feedback just described sets in. The E-P fluxes are enhanced and focused on the developing easterly jet, while the secondary circulation associated with the westerly shear on the upper flank of the easterly jet maintains the shallow broad aspect ratio of the jet. This feedback process saturates at some point, perhaps when the easterly anomalies become too strong to admit further wave driving.

\section{Relevance to the observed event}

We now consider to what extent the dynamics of the disruption observed in boreal winter of 2015/16 can be understood to follow the two-stage development just described. We make use of the ERA-Interim for this purpose but note that many of the relevant dynamical fields in the deep tropics are only weakly constrained by observations (Abalos et al. 2015; Kawatani et al. 2016).

Figure 8a shows time series of the equatorial zonalmean zonal wind and the meridional divergence of the meridional component of the E-P flux for the period from November 2015 to the end of March 2016. At the beginning of the period, the westerly winds extend from near the tropopause up to about $10 \mathrm{hPa}$, with weak vertical shear in a layer from 70 to $40 \mathrm{hPa}$. From the end of November through mid-January, a sequence of largeamplitude easterly eddy-forcing events occurs, centered roughly at the $80-\mathrm{hPa}$ level but extending up to about $30 \mathrm{hPa}$. In late November, a shallow easterly anomaly begins to form just about the $50-\mathrm{hPa}$ level; by midJanuary, this shallow region is centered somewhat below $40 \mathrm{hPa}$ and is about $4 \mathrm{~m} \mathrm{~s}^{-1}$ weaker than the westerly winds at $30 \mathrm{hPa}$. From mid-January through the end of February, there is a sequence of further large-amplitude eddy-forcing events, now more clearly centered at the level of the easterly anomalies, and by the beginning of March, net easterly winds have emerged.

The residual-mean vertical velocity shown in Fig. $8 \mathrm{~b}$ is perhaps weakly modulated by the shear zones associated with the emerging easterly jet (e.g., lighter red contours near $30 \mathrm{hPa}$ and darker contours near $55 \mathrm{hPa}$ from late February on), but in contrast to the dry dynamical core (cf. Fig. 3b), the secondary circulation is much weaker relative to the background upwelling.

The vertical structure of the meridional component of the resolved wave driving shown in Fig. 8a does not obviously match the vertical structure of the easterly jet that emerges. This is also true of the net (vertical and meridional) resolved wave driving (not shown). However, the results of the one-dimensional advective model suggest that the scale of the easterly jet is determined by the scale of the forcing. As mentioned above, given the relatively weak observational constraints in the tropics, particularly for such a derived quantity, one possible reason for this mismatch is that the resolved wave driving is not correctly captured by the reanalysis; another is the presence of unresolved wave driving. As a rough means of determining which aspects of the forcing are likely to be relevant to the developing jet, a highly idealized "back trajectory" has been overlaid on Fig. 8a, terminating at $40 \mathrm{hPa}$ on $1 \mathrm{March} 2016$. The heavy black line and shaded envelope corresponds to an upwelling velocity of $3 \pm 1 \times 10^{-4} \mathrm{~m} \mathrm{~s}^{-1}$, suggesting that the wave forcing in early winter at 50 or $60 \mathrm{hPa}$ is most relevant. Wave driving much below that level is unlikely to be so; since the winds do not change much in the westerly shear zone near $70 \mathrm{hPa}$, this forcing from the meridional fluxes is likely compensated by forcing from both resolved and unresolved vertical fluxes.

The scaling presented in section 4 provides a useful framework for understanding the similarities and differences between the observed event and the idealized dry dynamical core. Although the disruption occurs somewhat higher in the dry dynamical core (closer to 20 than $40 \mathrm{hPa}$ ), the vertical length scale of the easterly jets are quite comparable, with a half-width of about $2 \mathrm{~km}$. The background upwelling of about $3 \times 10^{-4} \mathrm{~m} \mathrm{~s}^{-1}$, however, is nearly an order of magnitude stronger in ERA-Interim than in the dry dynamical core. This corresponds to an advective time scale $T$ of about 60 days. 

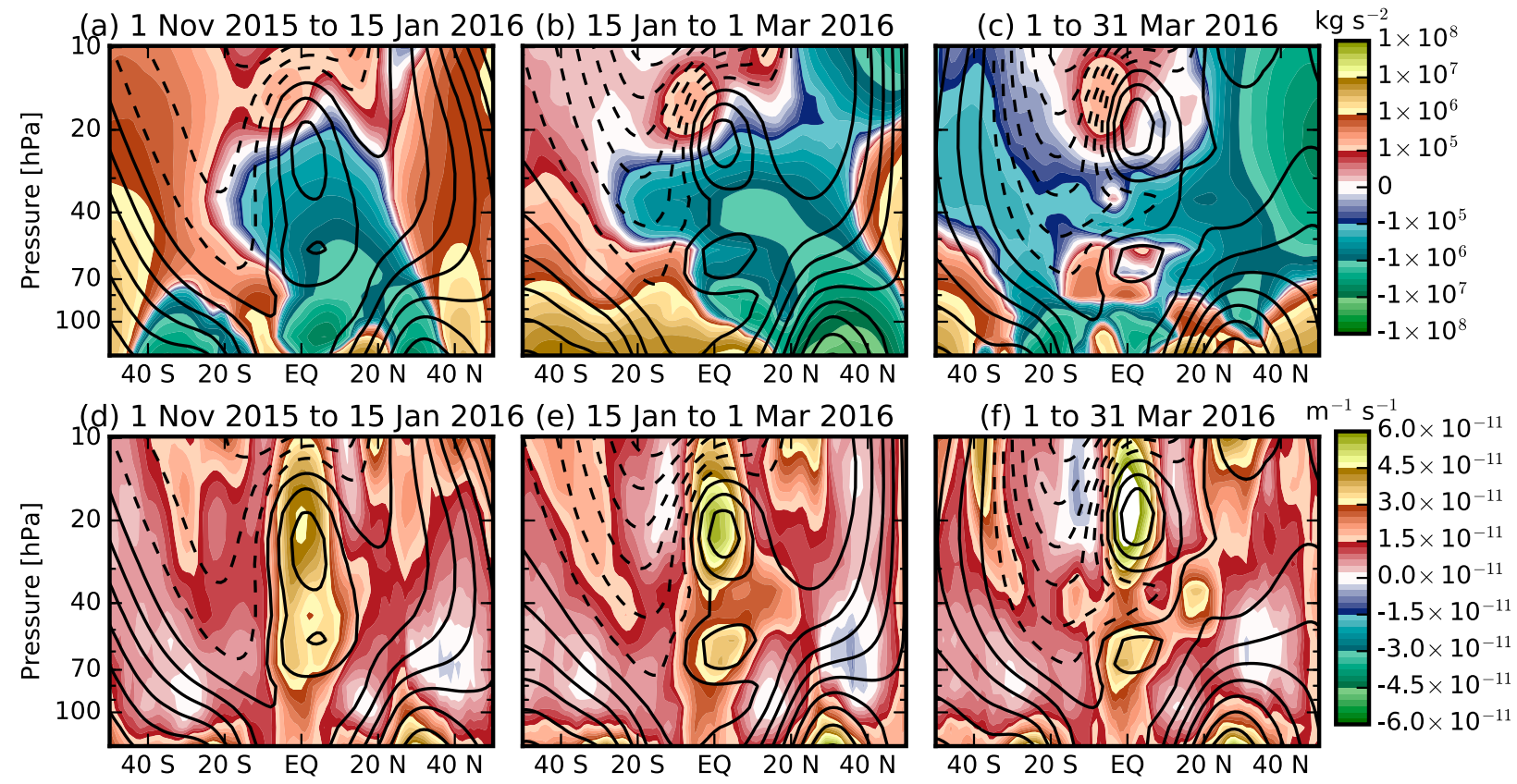

FIG. 9. (a)-(c) Meridional divergence of the meridional component of the E-P flux as an anomaly from the seasonal cycle for three periods (shading). (d)-(f) Meridional gradient of the quasigeostrophic potential vorticity for the same three periods (shading). In all panels, the zonal-mean zonal wind for the corresponding periods are indicated by the contours (interval: $5 \mathrm{~m} \mathrm{~s}^{-1}$ ).

The sensitivity parameter $\Gamma$ is more difficult to estimate for the real atmosphere than for the dry dynamical core, not least because the radiative time scale depends on the vertical scale of the associated temperature anomaly (Fels 1982). Estimates of this time scale vary (Mlynczak et al. 1999; Randel et al. 2002; Hitchcock et al. 2010), but given the vertical length scales, the relevant time scale is likely on the order of 10-30 days, corresponding to a value of $\alpha$ about twice that imposed in the dry dynamical core. The meridional length scale on the other hand is somewhat smaller (as shown below), so assuming a value of $\Gamma$ unchanged from that estimate for the dry dynamical core is reasonable. This is consistent with estimates from observations (Minschwaner et al. 2017). Since the threshold forcing $F_{c}$ depends quadratically on the background upwelling in (14), it is far larger for the real atmosphere than for the dry dynamical core. The assumptions just outlined give a value of roughly $5 \times 10^{-1} \mathrm{~m} \mathrm{~s}^{-1} \mathrm{day}^{-1}$, larger than all but the peak values of wave forcing shown in Fig. 8a. This suggests that the observed disruption is in the weak forcing regime, despite the considerably stronger wave forcing relative to the dry dynamical core (Fig. 1b). This is consistent with the relatively weak anomalies to the upwelling in the reanalysis data.

The meridional structure of the zonal wind and meridional E-P flux anomalies (relative to climatological values) is shown for three periods in Figs. 9a-c. During the period from November through mid-January, there are anomalously strong north-to-south cross-equatorial fluxes throughout most of the depth of the westerly QBO jet; however, the fluxes are strongest at the base of the jet, consistent with the episodes of convergence seen in Fig. 8a. The convergence of these fluxes is strongest below the level where the easterly jet ultimately emerges. These elevated fluxes can be traced to the top of the subtropical jet in the Northern Hemisphere. Figure 9d shows strong meridional gradients of PV along the equator during this period consistent with the tall westerly QBO jet and with Fig. 7d.

From mid-January through the end of February, a shallow layer of meridional E-P flux is seen, centered on the 40-hPa level where the jet is emerging (Fig. 8b). This feature was discussed by Coy et al. (2017), who pointed out that these fluxes are 6-9 times the standard deviation of the interannual variability from 1980 through 2014 and are thus unlikely to have occurred by chance alone. The developing easterly anomaly also leads to a weakening of the meridional PV gradients at the equator and a strengthening of the gradients on the northern subtropical flank of the anomaly (Fig. 9e). Both the E-P flux anomalies and PV gradients closely resemble those seen in the nudged simulation e1 (Figs. 7b,e), though the flux anomalies are somewhat stronger and the meridional length scale of the jet is somewhat smaller. 
(a) $\partial_{\phi} F^{(\phi)} 5 \mathrm{~S}$ to $5 \mathrm{~N}$

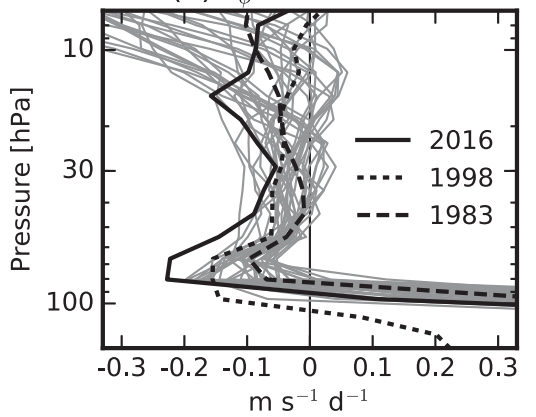

(b) $\mathrm{u} 60 \mathrm{hPa}$

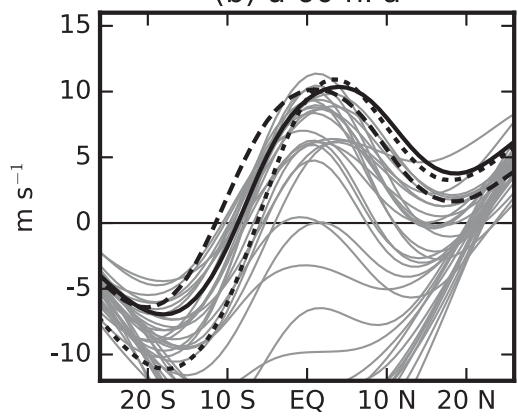

(c) $\mathrm{F}^{(\phi)} 60 \mathrm{hPa}$

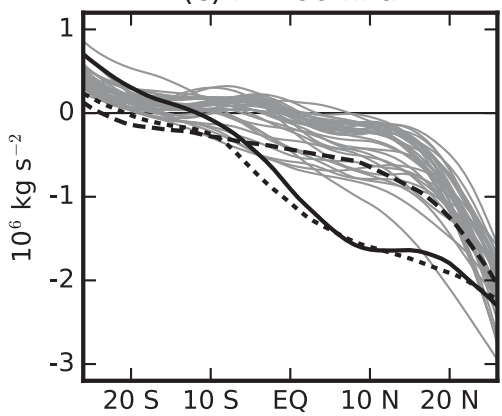

FIG. 10. (a) Profile of the wind tendency due to the meridional convergence of the meridional component of the E-P flux, averaged over $5^{\circ} \mathrm{S}-5^{\circ} \mathrm{N}$ and over the period from 1 Nov through $15 \mathrm{Jan}$ for each year from 1979/80 through 2015/16. Also shown are profiles of (b) zonal-mean zonal winds and (c) meridional component of the E-P flux at $60 \mathrm{hPa}$ for the same time periods. In (a)-(c), the winters $1982 / 83$, 1997/98, and 2015/16 are highlighted.

By March, the equatorial wave forcing at the level of the easterly jet shown in Fig. 8a has weakened substantially. However, there is still a shallow layer of elevated fluxes focused on the level of the easterly jet apparent during this period in Fig. 9c, which converges on the northward flank of the emerging jet. There are also regions of elevated PV gradients centered on the subtropical flanks of the easterly jet, similar in structure and magnitude to those seen in e2 (Fig. 7f). However, the increase in E-P fluxes in the Southern Hemisphere seen in e2 (Fig. 7c) is not apparent in this period. This may be explained by the deeper region of easterly winds separating the subtropical jet in the troposphere from the developing easterly jet, which was not present in the dry dynamical core integrations. The pattern of fluxes more closely resembles those seen in the free-running dry dynamical core integration (e.g., Fig. 2c).

On the basis of these comparisons with the dry dynamical core, we argue that the period from November through mid-January is analogous to the first stage of the disruptions in the idealized model (as discussed at the end of section 5), before significant zonal wind anomalies have formed. The eddy driving during this period can, from this perspective, be identified as the "trigger" for the event, and because of the vertical advection of the induced momentum anomalies, the relevant forcing during this period lies somewhat below the level at which the easterly jet ultimately emerges, likely near 50 or $60 \mathrm{hPa}$. The period from mid-January through March can then be identified with the second stage of the development of the disruption. The similarity in the E-P flux anomalies and meridional PV gradients between the reanalysis and the dry dynamical core integrations suggests that the dynamical feedback demonstrated in the latter through controlled experiments was also active at this point in the observed disruption.
This comparison suggests that to understand why the disruption occurred this year for the first time in the observational record, we must understand the nature and origin of the wave driving during the onset period from November through mid-January. Figure 10a shows the profile of equatorial wave forcing arising from the meridional component of the E-P flux for each 1 November-15 January period from 1980/81 through 2015/16. Since it has been suggested (Newman et al. 2016) that this event may be related to the large-amplitude El Niño event of this year, the winters of 1982/83 and $1997 / 98$, other years with large-amplitude El Niño events, are also highlighted. The wave forcing from 80 to $50 \mathrm{hPa}$ in the winter of 2015/16 was in fact the strongest easterly forcing in the reanalysis record by a substantial margin.

Because the E-P flux anomalies during this initial period appear to be propagating out of the tropospheric subtropical jet (Fig. 9a; this is confirmed by inspection of the vertical fluxes), it is plausible that these initial wavedriving events are associated with synoptic-scale eddies propagating higher and deeper into the tropics than normal. This could be a result of more westerly winds permitting more fluxes to propagate deep into the tropics. Figures $10 \mathrm{~b}$ and $10 \mathrm{c}$ explore this possibility, showing the zonal wind profile and meridional E-P flux along the $60-\mathrm{hPa}$ isobar. The zonal-mean zonal wind between the equator and $20^{\circ} \mathrm{N}$ was among the most westerly in the record, while the meridional E-P flux equatorward of about $25^{\circ} \mathrm{N}$, along with those during the winter of 1997/98, was substantially stronger than most other years. The fluxes in the deep tropics, however, remain weak compared to the climatological fluxes at higher latitudes, suggesting that what was unusual was not the overall level of wave activity at these levels but the degree to which this wave activity was able to propagate into the deep tropics and the degree to which this activity was absorbed at the equator, which is most 
obviously controlled by the zonal wind profile in the northern tropics. At the $60-\mathrm{hPa}$ level, these winds are most strongly controlled by the QBO itself, but the influence of El Niño, which is associated with a strengthening of the upper flanks of the subtropical jets, becomes more prominent lower in the stratosphere.

These results suggest the importance of several factors in leading to this disruption. First, the QBO westerlies need to be sufficiently deep for the wave driving to produce an isolated easterly jet (rather than simply encouraging or discouraging the descent of a shear zone). They also need to have reached the tropopause so that the associated westerlies are connected to the subtropical jet, permitting extratropical Rossby wave propagation into the deep tropics. The seasonal cycle of the subtropical jet, and the tendency for El Niño events to raise their upper flanks, suggests that the initial trigger is more likely to occur during El Niño events in Northern Hemisphere winter. The dynamical feedback may also be stronger in Northern Hemisphere winter because of the presence of stronger stationary waves, though the results of the dry dynamical core suggest that a topographic source is not essential. Finally, a sufficiently strong series of waveforcing events needs to occur to initiate the easterly anomaly. Given that these extratropical waves carry only easterly pseudomomentum, it is unlikely that an analogous westerly disruption could also occur.

\section{Conclusions}

A dry dynamical core configuration is described in which a steady-state, tall, equatorial westerly stratospheric jet is quasi-periodically disrupted by shallow easterly jets. These disruptions resemble in specific ways the disruption of the westerly QBO phase observed in early 2016.

Like the observed event, meridionally propagating eddies play a central role in producing the disruption. The easterly jets appear to organize the forcing produced by the eddies, suggesting the presence of a positive dynamical feedback. Further integrations demonstrate that reducing the extratropical topographic source of stationary waves increases the average time between the disruptions until they are eliminated altogether when the topography is removed.

Two possible mechanisms for such a feedback have been considered. The first involves the secondary circulation, which in the dry dynamical core is strong enough to overwhelm the background tropical upwelling. The impact of this process on the emerging jet was considered in the context of a one-dimensional advective model, subject to an imposed force. In this context, if an applied easterly force is stronger than a threshold value, the secondary circulation acts to confine the wind response in the vertical, and momentum is instead advected meridionally off the equator. The threshold force, $F_{c}=w_{0}^{2} N^{2} /\left(4 \alpha \beta L^{2}\right)$, depends on the background upwelling, static stability, radiative damping rate, the meridional length scale of the forcing, and the meridional gradient of the Coriolis parameter at the equator. For easterly forces weaker than this threshold, the wind response is advected upward. However, while this mechanism is likely important for establishing the aspect ratio of the easterly jet and maintaining its shallow vertical scale, it cannot explain the increasingly rapid strengthening of the easterly jet.

The second mechanism considered involves a feedback between the mean flow and the wave forcing. This feedback has been demonstrated in two sets of controlled experiments with the dry dynamical core. In the first set, easterly forces of varying strengths were externally imposed, modeled after the resolved wave forcing found prior to the disruptions. For magnitudes weaker than the composited force, a weak easterly anomaly is produced whose structure agrees with that predicted by the advective model. For magnitudes on the same order or stronger, the resolved wave forcing acts to strengthen the easterly jet, producing more than a fivefold amplification of the imposed force. In the second set, the zonal-mean equatorial winds were nudged toward a specified profile, allowing the extratropics and the eddies to evolve freely. Consistent with the first set of experiments, imposing a shallow easterly anomaly is found to produce a narrow region of enhanced wave fluxes arising from the top of the tropospheric subtropical jets and focused on the easterly anomalies. The enhanced fluxes are related to regions of enhanced meridional PV gradients that may be acting as a kind of "lightning rod" for drawing further wave activity toward the easterly jet.

These results suggest that the disruptions evolve through two stages. First, an initial series of weaker wave-forcing events produces a weak shallow easterly anomaly. Provided that the anomaly becomes sufficiently strong, the second stage begins when a positive feedback arises. Extratropical E-P fluxes amplify and focus on the developing easterly anomaly, producing the full easterly jet.

While one might be concerned about the sensitivity found in the dry dynamical core to, for instance, the hemispherical sensitivity parameter $\varepsilon$ (see section 2 ), the similarity between the large-scale flow in these integrations and analogous fields from ERA-Interim suggests the dynamical processes involved in the disruptions are robust. Indeed, evidence for a similar twostage evolution is found in the observed disruption. 
At the beginning of November 2015, the westerly phase of the QBO stretched from the tropopause up to about $10 \mathrm{hPa}$. A series of wave-forcing events centered near $70 \mathrm{hPa}$ but extending upward to $40 \mathrm{hPa}$ occurred from late November through about mid-January, producing a shallow easterly anomaly. This period can be identified with the first stage. By mid-January, the anomaly was nearly half the magnitude of the westerly phase of the QBO, and from mid-January through February, a series of further stronger wave-driving events occurred, centered on the 40-hPa level, leading to the full development of the easterly jet. The pattern of E-P fluxes and $\mathrm{PV}$ gradients in the meridional plane during this midJanuary-February period are quite similar to those obtained in the dry dynamical core, suggesting that the dynamical feedback identified in the dry dynamical core was active during the observed event. This period can thus be identified with the second stage.

The eddy feedback cannot explain the wave driving required to initiate the easterly anomaly by midJanuary. The advective model suggests that the wave driving just below $40 \mathrm{hPa}$ is relevant for this anomaly, and indeed, the wave driving at these levels during this period is found to be stronger than any other year in the ERA-Interim record. While this is likely to be due to a variety of factors, as discussed in the previous section, the zonal winds connecting the QBO westerlies to the upper flanks of the subtropical jets were also among the most westerly in the record, suggesting that the mean state was at least more conducive to this wave driving. Given the tendency for El Niño to strengthen the winds in this region (e.g., Simpson et al. 2011), it is likely that the strong El Niño event that occurred over the same period played a role in this event. Increasing concentrations of greenhouse gases are also expected to lead to this kind of circulation response (e.g., Shepherd and McLandress 2011), suggesting that such disruptions may become more likely, though the expected strengthening of tropical upwelling may counteract this to some extent.

While the wave driving during the onset of the disruption (i.e., during November-mid-January) may well have been statistically unlikely and difficult to forecast, the relevance of a feedback process suggested by the similarity of the observed event to the dry dynamical core integrations suggests that seasonal forecast models should have some skill in predicting the second stage. Failure to do so may imply a significant deficiency in seasonal forecast models of the subtropical winds near the tropopause; indeed, the sensitivity of the dry dynamical core integrations described above and the fact that such a disruption has not previously been observed and is thus a rare event is consistent with the idea that the occurrence of the disruption is highly sensitive to background conditions. Regardless of whether such disruptions recur or not, the disruption may thus prove to be a sensitive and valuable test of model performance in this critical region of the atmosphere.

Acknowledgments. PHi acknowledges support from European Research Council ACCI Grant Project 267760. PHa acknowledges support from the IDEX Chaires d'Attractivité programme of l'Université Fédérale de Toulouse, Midi-Pyrénées. TBi acknowledges helpful conversation with Mike Wallace regarding early work on the QBO. This work was partially supported by NASA GNSS Remote Sensing Science Team Grant NNX16AK37G. The National Center for Atmospheric Research is sponsored by the National Science Foundation. The source code and data for the dynamical core integrations are available from the corresponding author upon request.

\section{APPENDIX A}

\section{Momentum Budget in 1D Advective Model}

The advective model considered in section 4 can be justified by considering the zonally symmetric zonal momentum equation in Cartesian coordinates. In flux form, conservation of total momentum is clear:

$$
\partial_{t} u+\partial_{z}(u w)+\partial_{y}(u v)=\mathscr{F} .
$$

Taking a meridional average, designated by angle brackets, over a narrow region about the equator, if meridional variations from this average can be neglected in $u$ and $w$, this leads to

$\partial_{t}\langle u\rangle+\langle w\rangle \partial_{z}\langle u\rangle+\langle u\rangle \partial_{z}\langle w\rangle+\langle u\rangle \partial_{y}\langle v\rangle=\mathscr{F}$,

from which (9) follows after use of the continuity equation. Variations in $w$ with height then imply corresponding meridional transport of mass and momentum out of the equatorial region.

\section{APPENDIX B}

\section{Threshold Behavior in the Advective Model}

Adopting the scaling discussed in the text, the vertical derivative of (9) is

$$
\partial_{t} u_{z}+\left(1-u_{z}\right) \partial_{z} u_{z}=\partial_{z} \mathscr{F},
$$

where all symbols are now their nondimensional equivalents. (Note the forcing scale is $2 F_{c}$.) This is a 
linear first-order partial differential equation for the vertical shear $u_{z}=\partial_{z} u$ that can be solved along characteristics

$$
\begin{gathered}
\frac{d z}{d s}=1-u_{z}, \\
\frac{d u_{z}}{d s}=\partial_{z} \mathscr{F} .
\end{gathered}
$$

The vertical velocity of these characteristics is not the upwelling velocity (which would be $1-u_{z} / 2$ ). For the piecewise quadratic forcing in (15), this leads to a second-order ordinary differential equation:

$$
\frac{d^{2} u_{z}}{d s^{2}}+F u_{z}=\left\{\begin{array}{lll}
F & \text { if } & 0<z<2 \\
0 & \text { otherwise }
\end{array}\right.
$$

Solutions to (B3) for easterly forces $(F>0)$ are trigonometric, while for westerly forces $(F<0)$, they are exponential; we consider the former.

The switch-on problem considered in the text assumed an initial vertical profile of shear $u_{z}(t=0, z)=U^{\prime}(z)$ and no shear at the base of the domain for all time $u_{z}(t, z=0)=0$. The steady-state solution is determined by characteristics starting at the base of the domain; of interest here is the behavior of those that start within the forcing region when the force is switched on. For now the initial shear is taken to vanish $\left(U^{\prime}=0\right)$.

The solution along characteristics is

$$
\begin{aligned}
& u_{z}(s)=\sqrt{F}\left(z_{0}-1\right) \sin \sqrt{F} s+1-\cos \sqrt{F} s, \quad s<s_{c}, \\
& z(s)=\frac{1}{\sqrt{F}} \sin \sqrt{F} s+\left(z_{0}-1\right) \cos \sqrt{F} s+1, \quad s<s_{c},
\end{aligned}
$$

where $s$ parameterizes the characteristics, and the fact that $\left(d u_{z} / d s\right)(s=0)=f^{\prime}\left(z_{0}\right)$ at the height $z_{0}=z(0)$ where the characteristic is initialized has been used. The characteristics leave the forcing layer when $z\left(s_{c}\right)=2$, after which the shear (and thus the vertical velocity) remains constant. The time $s_{c}$ is given by

$$
\begin{aligned}
\sqrt{F} S_{c} & =\arcsin R+\arcsin \left(1-z_{0}\right) R, \\
R & =\left[F^{-1}+\left(1-z_{0}\right)^{2}\right]^{-1 / 2} .
\end{aligned}
$$

Within the forcing layer, characteristics that enter the domain after the onset of the forcing will first be subject to the lower flank of the imposed forcing that strengthens with height, producing easterly shear. They then accelerate upward until they pass $z=1$, after which they are subject to the upper flank of the imposed forcing that weakens with height, reducing the shear and slowing their ascent. In steady state (e.g., for $z_{0}=0$ ), this recovers (11).

Consistent with the intuition that the easterly forcing should tend to accelerate the ascent of the parcels, those trajectories that start at $z_{0}=0$ reach the top of the forcing layer, no later than $\pi z_{f} / 4 \sqrt{\Gamma f_{0}}$ (in dimensional terms) after they enter. Trajectories that begin above the midpoint of the forcing layer, for which $z_{0}>1$, are subject only to the upper flank of the forcing and do not always reach the top of the forcing layer.

This can be seen, for instance, by considering (B4b) for the set of trajectories that start at $t=0$. At the time $s_{0}=\pi / 2 \sqrt{F}, z\left(s_{0}\right)=F^{-1 / 2}+1$ becomes independent of the initial condition $z_{0}$, provided that the trajectories have not yet left the forcing layer. This will be the case for at least some trajectories if $F>1$. In this case, a cusp forms with easterly shear below and westerly shear above. The height $z\left(s_{0}\right)$ at which the cusp forms always lies within the forcing layer, above the midpoint.

More general forcing profiles can also be considered. Multiplying together (B2a) and (B2b) yields

$$
\frac{d\left[u_{z}-(1 / 2) u_{z}^{2}\right]}{d s}=\frac{d \mathscr{F}}{d s},
$$

which can be integrated to find

$$
\frac{d z}{d s}(s)= \pm \sqrt{\left(U^{\prime}-1\right)^{2}-2[\mathscr{F}(s)-\mathscr{F}(0)]} .
$$

Characteristics turn over if they reach a height at which

$$
\mathscr{F}[z(s)]-\mathscr{F}\left(z_{0}\right)=\frac{1}{2}\left(U^{\prime}-1\right)^{2} .
$$

For $U^{\prime}=0$, this will necessarily occur for an arbitrary localized easterly force if the maximum amplitude of $\mathscr{F}$ is greater than 1 or, equivalently, if its dimensional magnitude is greater than $F_{c}=w_{0}^{2} / 4 \Gamma$.

\section{REFERENCES}

Abalos, M., B. Legras, F. Ploeger, and W. J. Randel, 2015: Evaluating the advective Brewer-Dobson circulation in three reanalyses for the period 1979-2012. J. Geophys. Res. Atmos., 120, 7534-7554, https://doi.org/10.1002/2015JD023182.

Andrews, D. G., J. R. Holton, and C. B. Leovy, 1987: Middle Atmosphere Dynamics. International Geophysics Series, Vol. 40, Academic Press, 489 pp.

Coy, L., P. A. Newman, S. Pawson, and L. R. Lait, 2017: Dynamics of the disrupted 2015/16 quasi-biennial oscillation. J. Climate, 30, 5661-5674, https://doi.org/10.1175/JCLI-D-16-0663.1.

Dee, D. P., and Coauthors, 2011: The ERA-Interim reanalysis: Configuration and performance of the data assimilation 
system. Quart. J. Roy. Meteor. Soc., 137, 553-597, https:// doi.org/10.1002/qj.828.

Dunkerton, T. J., 1991: Nonlinear propagation of zonal winds in an atmosphere with Newtonian cooling and equatorial wavedriving. J. Atmos. Sci., 48, 236-263, https://doi.org/10.1175/ 1520-0469(1991)048<0236:NPOZWI >2.0.CO;2.

Fels, S. B., 1982: A parameterization of scale-dependent radiative damping rates in the middle atmosphere. J. Atmos. Sci., 39, 1141-1152, https://doi.org/10.1175/1520-0469(1982)039<1141: APOSDR $>2.0 . \mathrm{CO} ; 2$

Fyfe, J., and I. M. Held, 1990: The two-fifths and one-fifth rules for Rossby wave breaking in the WKB limit. J. Atmos. Sci., 47, 697-706, https://doi.org/10.1175/1520-0469(1990)047<0697: TTFAOF $>2.0 . \mathrm{CO} ; 2$.

Giorgetta, M. A., L. Bengtsson, and K. Arpe, 1999: An investigation of QBO signals in the East Asian and Indian monsoon in GCM experiments. Climate Dyn., 15, 435-450, https://doi.org/10.1007/s003820050292.

Hitchcock, P., T. G. Shepherd, and S. Yoden, 2010: On the approximation of local and linear radiative damping in the middle atmosphere. J. Atmos. Sci., 67, 2070-2085, https://doi.org/ 10.1175/2009JAS3286.1.

Hoskins, B. J., and A. J. Simmons, 1975: A multi-layer spectral model and the semi-implicit method. Quart. J. Roy. Meteor. Soc., 101, 637-655, https://doi.org/10.1002/ qj.49710142918.

Kawatani, Y., K. Hamilton, K. Miyazaki, M. Fujiwara, and J. A. Anstey, 2016: Representation of the tropical stratospheric zonal wind in global atmospheric reanalyses. Atmos. Chem. Phys., 16, 6681-6699, https://doi.org/10.5194/acp-16-6681-2016.

Laprise, R., and C. Girard, 1990: A spectral general circulation model using a piecewise-constant finite-element representation on a hybrid vertical coordinate system. J. Climate, 3, 32-52, https://doi.org/10.1175/1520-0442(1990)003<0032: ASGCMU $>2.0 . \mathrm{CO} ; 2$.

Lindzen, R. S., and J. R. Holton, 1968: A theory of the quasibiennial oscillation. J. Atmos. Sci., 25, 1095-1107, https://doi.org/ 10.1175/1520-0469(1968)025<1095:ATOTQB >2.0.CO;2.

Marsh, D. R., M. J. Mills, D. E. Kinnison, J.-F. Lamarque, N. Calvo, and L. M. Polvani, 2013: Climate change from 1850 to 2005 simulated in CESM1(WACCM). J. Climate, 26, 7372-7391, https://doi.org/10.1175/JCLI-D-12-00558.1.

Minschwaner, K., H. Su, and J. H. Jiang, 2017: The upward branch of the Brewer-Dobson circulation quantified by tropical stratospheric water vapor and carbon monoxide measurements from the Aura Microwave Limb Sounder. J. Geophys. Res. Atmos., 121, 2790-2804, https://doi.org/ 10.1002/2015JD023961.

Mlynczak, M. G., C. J. Mertens, R. R. Garcia, and R. W. Portmann, 1999: A detailed evaluation of the stratospheric heat budget: 2. Global radiation balance and diabatic circulations. J. Geophys. Res., 104, 6039-6066, https://doi.org/10.1029/ 1998JD200099.
Newman, P. A., L. Coy, S. Pawson, and L. R. Lait, 2016: The anomalous change in the QBO in 2015-2016. Geophys. Res. Lett., 43, 8791-8797, https://doi.org/10.1002/ 2016GL070373.

Osprey, S. M., N. Butchart, J. R. Knight, A. A. Scaife, K. Hamilton, J. A. Anstey, V. Schenzinger, and C. Zhang, 2016: An unexpected disruption of the atmospheric quasi-biennial oscillation. Science, 353, 1424-1427, https://doi.org/10.1126/ science.aah4156.

O'Sullivan, D., 1997: Interaction of extratropical Rossby waves with westerly quasi-biennial oscillation winds. J. Geophys. Res., 102, 19461-19469, https://doi.org/10.1029/97JD01524.

Plumb, R. A., and R. C. Bell, 1982: A model of the quasibiennial oscillation on an equatorial beta-plane. Quart. J. Roy. Meteor. Soc., 108, 335-352, https://doi.org/10.1002/ qj. 49710845604

Polvani, L. M., and P. J. Kushner, 2002: Tropospheric response to stratospheric perturbations in a relatively simple general circulation model. Geophys. Res. Lett., 29, 1114, https://doi.org/ 10.1029/2001GL014284.

Randel, W. J., R. R. Garcia, and F. Wu, 2002: Time-dependent upwelling in the tropical lower stratosphere estimated from the zonal-mean momentum budget. J. Atmos. Sci., 59, 2141-2152, https://doi.org/10.1175/1520-0469(2002)059<2141: TDUITT $>2.0 . \mathrm{CO} ; 2$

Reed, R. J., 1964: A tentative model of the 26-month oscillation in tropical latitudes. Quart. J. Roy. Meteor. Soc., 90, 441-466, https://doi.org/10.1002/qj.49709038607.

Scinocca, J. F., and P. H. Haynes, 1998: Dynamical forcing of stratospheric planetary waves by tropospheric baroclinic eddies. J. Atmos. Sci., 55, 2361-2392, https://doi.org/10.1175/ 1520-0469(1998)055<2361:DFOSPW >2.0.CO;2.

Shepherd, T. G., and C. McLandress, 2011: A robust mechanism for strengthening of the Brewer-Dobson circulation in response to climate change: Critical-layer control of subtropical wave breaking. J. Atmos. Sci., 68, 784-797, https://doi.org/ 10.1175/2010JAS3608.1.

Simmons, A. J., and D. M. Burridge, 1981: An energy and angularmomentum conserving vertical finite-difference scheme and hybrid vertical coordinates. Mon. Wea. Rev., 109, 758-766, https://doi. org/10.1175/1520-0493(1981)109<0758:AEAAMC > 2.0.CO;2.

Simpson, I. R., T. G. Shepherd, and M. Sigmond, 2011: Dynamics of the lower stratospheric circulation response to ENSO. J. Atmos. Sci., 68, 2537-2556, https://doi.org/10.1175/JAS-D-11-05.1.

Wallace, J. M., 1967: On the role of mean meridional motions in the biennial wind oscillation. Quart. J. Roy. Meteor. Soc., 93, 176185, https://doi.org/10.1002/qj.49709339604.

_ quasi-biennial oscillation. J. Atmos. Sci., 25, 280-292, https:// doi.org/10.1175/1520-0469(1968)025<0280:ADNMOT>2.0.CO;2.

Yao, W., and C. Jablonowski, 2015: Idealized quasi-biennial oscillations in an ensemble of dry GCM dynamical cores. J. Atmos. Sci., 72, 2201-2226, https://doi.org/10.1175/ JAS-D-14-0236.1. 